\title{
Structure and mobility of lactose in lactose/sodium
}

\section{montmorillonite nanocomposites}

Joel Hellrup, ${ }^{\dagger}$ Michael Holmboe, ${ }^{+}$Karol P. Nartowski, ${ }^{\S}$ Yaroslav Z. Khimyak, ${ }^{\S}$ and Denny

$\operatorname{Mahlin}^{*},+$

${ }^{\dagger}$ Department of Pharmacy, Uppsala University, Uppsala, Sweden

¥ Department of Chemistry, Umeå University, Umeå, Sweden

$\S$ School of Pharmacy, University of East Anglia, Norwich Research Park, Norwich, UK

\section{ABSTRACT}

This study aims at investigating the molecular level organization and molecular mobility in montmorillonite nanocomposites with the uncharged organic low-molecular-weight compound lactose commonly used in pharmaceutical drug delivery, food technology, and flavoring. Nanocomposites were prepared under slow and fast drying conditions, attained by drying at ambient conditions and by spray-drying, respectively. A detailed structural investigation was performed with modulated differential scanning calorimetry, powder X-ray diffraction, solidstate nuclear magnetic resonance, scanning electron microscopy, microcalorimetry, and molecular dynamic simulations. The lactose was intercalated in the sodium montmorillonite interlayer space regardless of the clay content, drying rate, or humidity exposure. Although, the spray-drying resulted in higher proportion of intercalated lactose compared with the drying under 
ambient conditions, non-intercalated lactose was present at $20 \mathrm{wt} \%$ lactose content. This indicates limitations in maximum load capacity of nonionic organic substances into the montmorillonite interlayer space. Furthermore, a fraction of the intercalated lactose in the cospray-dried nanocomposites diffused out from the clay interlayer space upon humidity exposure. Also, the lactose in the nanocomposites demonstrated higher molecular mobility than that of neat amorphous lactose. This study provides a foundation for understanding functional properties of nanocomposites, such as loading capacity and physical stability.

\section{INTRODUCTION}

The main constituent of bentonite, montmorillonite (MMT), gain much scientific interest as a material with wide array of potential use including catalysis, functional clay-polymer nanocomposites or as a material for nuclear waste storage. ${ }^{1}$ MMT is a 2:1 phyllosilicate mineral that belongs to the smectite group and consists of clay mineral particles made of turbostratically stacked MMT sheets, about $10 \AA$ thick. ${ }^{2,3}$ Imperfections in the MMT crystal lattice due to isomorphous substitution induce a negative net charge which is counter-balanced by cations such as $\mathrm{Na}^{+}$in the interlayer space and at the outer basal surfaces. ${ }^{4}$ Its layered structure and extremely high surface area enable intercalation of large quantities of other substances leading to nanomaterials with novel and/or improved properties compared to a simple mixture of the two components. ${ }^{5}$ It has been reported that clay-polymer nanocomposites demonstrate improved mechanical properties, increased heat resistance, gas permeability, flammability and biodegradability of polymers. ${ }^{5}$ MMT has been used recently as an excipient in pharmaceutical applications, including transdermal formulations, tablets for oral administration, and as an extended release agent for tablets. ${ }^{6-10}$ Furthermore, inclusion of photodegradable drug molecules within MMT may increase the photostability. ${ }^{11}$ In this context, we further explore possible use of 
MMT as a pharmaceutical excipient. Use of naturally sourced and regulatory accepted materials may lead to a development of novel functional composites with no need for extensive documentation which is associated with approval of new excipients for market authorization.

The arrangement of clay sheets in mixtures with other compounds may change the properties of the nanocomposite significantly. On a microscopic level, MMT can either exist in an ordered layered structure, and thereby form stacked particles, also denoted tactoids, or be exfoliated and dispersed in the mixture with another solid or semisolid material. ${ }^{5}$ Furthermore, several (metastable) phases can be present simultaneously in nanocomposites of MMT. These include neat MMT, MMT with the organic component intercalated into its interlayer space and the amorphous organic compound. The structure and uniformity of clay-based materials depends on the preparation procedure and clay/organic phase ratio. ${ }^{5}$

There is significant amount of published research on organic polymer-clay nanocomposites, but only few report on MMT combined with low-molecular-weight organic compounds including peptides and amino acids. ${ }^{7-19}$ In these reports, the most important mechanism involved in intercalation into MMT is cationic exchange. ${ }^{7-9,12,13,19}$ Anionic and nonionic compounds have also been demonstrated to interact with MMT. ${ }^{10,15-18}$

In this study, lactose was chosen as a model nonionic organic substance and co-spray-dried with Na-MMT to form nanocomposites in with different host-guest ratios. Lactose is a hydrophilic low-molecular-weight compound $(342.3 \mathrm{~g} / \mathrm{mol})$ and one of the most commonly used excipients in pharmaceutical drug delivery, food technology, and flavoring. ${ }^{20}$ It is well-known that lactose turns amorphous upon spray-drying when the solvent evaporation is very rapid during the spray-drying process. The molecular structure of this nonionic compound displays 
many hydrogen bonding groups, making it of interest for studies of interactions and mixing behavior in nanocomposite with the negatively charged surfaces and counter ions of MMT.

The material properties of powdered lactose and similar disaccharides are highly dependent on its solid state form. For instance, the tablet binding properties of $\alpha$-lactose monohydrate can be improved by spray-drying a suspension of fine milled $\alpha$-lactose monohydrate in a solution of lactose, thereby introducing amorphous regions into the excipient. ${ }^{20}$ Also, amorphous disaccharides are important in preserving protein structure in freeze-dried formulations. ${ }^{21}$ The main disadvantage of disordered systems is their thermodynamic instability. Physical stability against recrystallization of an amorphous material is often improved through processing of the drug with a polymer to form an amorphous mixture. Recently it has been demonstrated that increased stabilization of amorphous drug and excipients can be obtained by mixing these with inert clay or silicate particles, or by nanoconfinement within mesoporous silica. ${ }^{22-27}$ The advanced studies of structure and dynamics in such materials at different lengths scales, that is, from molecular level to meso- and microstructure are needed to provide a more detailed insight into the origins of control of physical stability and compaction properties.

This study aims at investigating the nanoscale structure of composites consisting of Na-MMT and lactose, formed when drying a water dispersion of the components. An understanding of the driving forces behind interlayer space intercalation of lactose and nanoscale domain formation is sought by studying the solid state (that is, the basal spacing of the MMT and the properties of the amorphous phase), interactions between lactose and MMT, and the molecular mobility of the nanocomposites formed at different drying conditions and after humidity exposure. 


\section{EXPERIMENTAL SECTION}

\section{Materials}

Alpha-lactose monohydrate (Ph. Eur., Fluka Analytical, Sigma-Aldrich, Buchs, Germany) was used to prepare $41 \mathrm{mM}$ solutions using de-ionized water. The sodium montmorillonite, Cloisite $^{\circledR}$ $\mathrm{Na}^{+}$(Na-MMT), was kindly provided by BYK Additives \& Instruments (Wesel, Germany).

\section{Clay mineral characterization}

Laser diffraction particle size analysis on suspended Na-MMT (see below for suspension preparation) was conducted on a LS 230 (Beckman-Coulter, Brea, CA). Three measurements were done on each of two separately prepared suspensions. The size of suspended Na-MMT was also determined by photon correlation spectroscopy (Zetasizer 4000, Malvern Instruments, Worcestershire, UK). Two measurements were performed on each of two separately prepared suspensions.

The cryogenic-Transmission Electron Microscopy (cryo-TEM) specimens of Na-MMT was prepared according to method described by Bodvik et al. ${ }^{28}$ The grid with the vitrified sample was transferred to the Zeiss Libra 120 TEM (Oberkochen, Germany) using a Gatan CT3500 (Pleasanton, CA) cryo-transfer apparatus. The specimen was kept at a temperature below $108 \mathrm{~K}$ during both transfer and examination.

\section{Sample preparation}

Na-MMT (4.9 g/L) was dispersed by sonicating it in water with an ultrasonic bath (Branson 5210 , Soest, Netherlands) for $1 \mathrm{~h}$ and then stirred for $18 \mathrm{~h}$ in room temperature followed by $4 \mathrm{~h}$ in a water bath at $353 \mathrm{~K}$. The suspensions were mixed with water and a lactose solution (41 $\mathrm{mM})$ 
that had equilibrated with regard to spontaneous mutarotation, in proportions leading to a combined fraction dry material (clay + lactose) of $6.5 \mathrm{wt} \%$ and $0-100 \mathrm{wt} \% \mathrm{Na}-\mathrm{MMT}$ in lactose.

The prepared suspensions were co-spray-dried with a Mini Spray Dryer B-290 (Büchi, Flawil, Switzerland). A nozzle tip of $0.7 \mathrm{~mm}$ and nozzle screw cap of a diameter of $1.5 \mathrm{~mm}$ were used. The spray-dryer was operated in an open mode, whereby the drying gas was passed through a filter and a dehumidifier (B-296). A high-performance cyclone was used. During the spraydrying, volume flow, nozzle cleaning, inlet temperature, spray air flow, and feed rate were set at $38 \mathrm{~m}^{3} / \mathrm{h}$, level 2, $423 \mathrm{~K}, 473 \mathrm{l} / \mathrm{h}$, and $4 \mathrm{ml} / \mathrm{min}$ respectively.

The suspensions were also poured into petri dishes to let the water evaporate under ambient conditions for 4 weeks. The formed films were milled into powders with a mortar and pestle. Finally, the powders were dried at $353 \mathrm{~K}$ for 10 min with a HR73 Halogen Moisture Analyzer (Mettler Toledo, Greifensee, Switzerland).

The prepared samples were placed over silica gel until examination or further treatment. Cospray-dried nanocomposites samples were also stored for $1-5$ days in a sealed container at room temperature above a saturated $\mathrm{KNO}_{3}$ solution, controlling the relative humidity $(\mathrm{RH})$ to $94 \% \mathrm{RH}$. The associated water was then dried at $353 \mathrm{~K}$ for $10 \mathrm{~min}$. These samples will be referred to as humidity stressed nanocomposites.

\section{Thermogravimetric analysis}

The lactose content was quantified using a thermogravimetric approach. In the first set of experiments, we used a TQ 500 thermogravimetric analyzer (TA Instruments, New Castle, DE) to quantify residual water and loss of organic content, that is, the lactose, up to $903 \mathrm{~K}$. All samples $(5-10 \mathrm{mg})$ were loaded on platinum pans and heated from room temperature to $383 \mathrm{~K}$ with heating rate of $5 \mathrm{~K} / \mathrm{min}$ to quantify residual water followed by a heating to $903 \mathrm{~K}$ and 
isothermal calcination for 45 minutes. A sample and a balance nitrogen purge flow of $25 \mathrm{~mL} / \mathrm{min}$ and $10 \mathrm{~mL} / \mathrm{min}$ were applied, respectively. All results were analyzed using TA Instruments Universal Analysis 2000 (TA Instruments, New Castle, DE). Due to only partial decomposition of the lactose in nitrogen atmosphere, calcination at higher temperatures in air atmosphere was required. The materials were accurately weight onto ceramic dishes and heated from room temperature with a heating rate of $20 \mathrm{~K} / \mathrm{min}$ to $1073 \mathrm{~K}$. The samples were kept in an aerated atmosphere at $1073 \mathrm{~K}$ for $10 \mathrm{~h}$ then cooled to room temperature and weighed again. The weight of the residual powder corresponds to the Na-MMT content.

\section{Scanning electron imaging}

The co-spray-dried nanocomposites and the humidity stressed nanocomposites were imaged with scanning electron microscopy. The samples were sputter coated for $120 \mathrm{~s}$ at $2 \mathrm{kV}$ with gold using a Polaron SC7640 sputter coater (Quorum Technologies Ltd, Newhaven, UK) and imaged using a LEO 1550 (Zeiss, Oberkochen, Germany) operated at $2.0 \mathrm{kV}$.

\section{Powder X-ray diffraction}

Powder X-ray diffraction (XRD) was measured using a Bruker D8 Advance coupled 2 $\theta-\theta$ diffractometer with a position sensitive detector, LynxEye (Bruker AXS, Inc., Madison, WI). Specimens for XRD were placed in Ø $25 \mathrm{~mm}$ holders and compacted to produce an even surface. The samples were rotated at $66.6 \mathrm{rpm}$ and irradiated with $\mathrm{X}$-rays generated by a $\mathrm{CuK} \alpha_{1}$ tube operated at $40 \mathrm{kV}$ and $40 \mathrm{~mA}$ with a wavelength of $1.5406 \AA$. A motorized primary divergence slit with $0.1^{\circ}$ opening was used. A step size of $0.02^{\circ}$ with an integration time of $1.8 \mathrm{~s}$ was used from $2-80^{\circ} 2 \theta$. The measurements were performed at room temperature, that is, $c a .295 \mathrm{~K}$ and the RH was $c a .25-35 \% \mathrm{RH}$. 


\section{Molecular dynamic simulations}

Molecular dynamic simulations (MD) were performed using the MD code LAMMPS $^{29}$ to calculate the average atomic structure in the interlayer space, in order to find the relation between the lactose/Na-MMT nanocomposite basal spacing $\left(\mathrm{d}_{001}\right)$ with varying lactose and water loading, and to calculate the one-dimensional layer structure factors, $G$, needed for interpretation of the XRD results. ${ }^{12,13,30,31}$ Since only a limited number of similar organic/water/clay studies have previously been reported, finding and implementing a self-consistent set of force-fields for organic/water/clay is not trivial. In this study, a topology built from $\alpha$-lactose with the charmmgui server and the ch2lmp LAMMPS tool was used with the CHARMM36 all-atom carbohydrate force-field to describe the lactose molecules. A comparison of the simulated bond lengths and bonded angles of this molecule in water with the reported crystalline structure can be found in the supporting information. ${ }^{32} 33,34$ As is shown in Figure S6, bond lengths generally differed by less than $0.02 \AA(\sim 1.5 \%)$ from to the original bond lengths, and all atoms having bond lengths differing by more than $0.04 \AA$ involved hydrogen atoms. Analogously, all angles differing by more than $2^{\circ}$ (more than $\sim 2 \%$ ) belonged to $\mathrm{C}-\mathrm{O}-\mathrm{H}$ groups. Hence the overall parameterization of the lactose molecule with the charmm all36_carb force field was quite satisfactory, where smaller discrepancies in bond lengths and angles of the lactose hydrogen atoms possibly could be explained by their sensitivity to solvation and interactions with the surrounding water molecules. The clay lattice was constructed from a pyrophyllite structure ${ }^{35}$ subjected to isomorphic substitution to yield a surface charge of $-0.11 \mathrm{C} / \mathrm{m}^{2}$ and modeled with Clayff, ${ }^{36}$ which originally was parameterized with the SPC water model, ${ }^{37}$ as it is well-known to reproduce the structure and outer dimensions of clay mineral unit cells, whereas the interaction parameters for the $\mathrm{Na}^{+}$ ions were taken from Joung and Cheatham. ${ }^{38}$ 
9 different simulations were performed with 0 -32 (in steps of 4) randomly placed $\alpha$-lactose molecules, initially hydrated with 2,700 TiP3P water molecules between two montmorillonite layers consisting of $6 \times 4$ unit cells in the $\mathrm{x}$ and $\mathrm{y}$ directions, respectively, yielding equilibrated box sizes of $31 \pm 0.1 \times 36.1 \pm 0.1 \AA$ in the $\mathrm{x}$ and $\mathrm{y}$ directions (within $0.5 \%$ of the theoretical size), respectively, and $80-90.1 \AA$ in the $\mathrm{z}$ direction depending on the lactose content. All simulations were performed with a 1 fs timestep in the $\mathrm{NP}_{\mathrm{zz}} \mathrm{T}$ ensemble with periodic boundary conditions in all directions. After $4 \mathrm{~ns}$ of equilibration and depending of the number of lactose molecules, the simulation cells contained in total 9,076-10,516 particles and approximated 3.1 $\times 3.6 \times(8.2-9.1)$ $\mathrm{nm}$. In order to check the consistency of our simulations, two different sets of simulations were performed, differing only in the total simulation time. Hence, following equilibration, the water molecules in each of the two sets of simulations were sequentially removed through 45 evaporative steps ${ }^{39}$ using production runs of $100-200$ or $250-500$ ps between each evaporative step (increasing the simulation time with decreasing water loading).

\section{XRD profile fitting}

One-dimensional XRD profile modeling was performed to calculate the average basal spacing and estimate the amount of intercalated lactose in the nanocomposite Na-MMT particles. This was accomplished using a recursive mixed layer modeling algorithm similar to the popular

Newmod software which can handle random interstratification of clay phases ${ }^{40}$ albeit enabling global fitting to experimental data with custom layer types and log normal particle size distributions. In one-dimensional XRD profile modeling of a single phase, the intensity of diffracted X-rays can generically be described by:

$I(2 \theta)=L P G^{2} \phi$ 
where $L P$ is the particle orientation and instrument dependent Lorentz-polarization factor and $\phi$ is the periodic interference function describing the unit cell and crystallite size dependent Bragg reflections. The relative magnitude of $I(2 \theta)$ and the $00 l$ reflections is, however, modulated by the highly non-linear layer structure factor $G .{ }^{31}$

$G=\sum_{n} p_{n} f_{n} \cos \left(4 \pi z_{n} \sin (\theta) / \lambda\right)+i \sum_{n} p_{n} f_{n} \sin \left(4 \pi z_{n} \sin (\theta) / \lambda\right)$

The $G$ factor depends on the electron density in the unit cell, and is thus affected by the number $(p)$ and positions $(z)$ of all $n$ atom types with their respective atomic scattering factors $(f)$, in the nanocomposite three-component unit cell containing the clay lattice, lactose and water molecules. Furthermore, in order to model two or more interstratified layered clay phases, the fraction of each phase and their mixing order must also be taken into account, making it necessary to incorporate terms covering all possible combinations of $G$ and $\Phi$, for each clay layer and interlayer type into Equation $1 .^{31}$

Initially 7 different $G$-factors were calculated from the MD trajectories of lactose, $\mathrm{Na}^{+}$ions and water molecules, for systems having $\mathrm{d}_{001}$ values approximating the experimental data (using Braggs law). For the clay lattice however, the frequently used semi-empirical structural parameters were used to describe the clay lattice. ${ }^{31}$ This is because the non-bonded Clayff parameters do not necessarily reproduce the inner unit cell atomic positions as well as the outer unit cell dimensions of montmorillonite (the oxygen basal-basal plane distance was $\sim 6.6 \AA$ compared to the tabulated value of $6.54 \AA$ ). The $G$-factors was calculated with 0,4 , or 8 lactose molecules with 7.5, 5, or 0 water molecules per unit cell for the $14 \AA$ peak, respectively, and 0,8 , 12 , or 16 lactose with $12.5,10,7.5$, or 5 water molecules per unit cell for the $18 \AA$ peak. These $3+4 G$-factors hence allowed for $3 * 4=12$ different $G$-factor combinations to be used to model the 
interlayer lactose content. For neat Na-MMT, four additional $G$-factors were calculated corresponding to $9.6,12.4,15.6,18.9 \AA$, representing the $0 \mathrm{~W}, 1 \mathrm{~W}, 2 \mathrm{~W}$ and the $3 \mathrm{~W}$ water layer hydration state. As recommended by Ferrage et al., ${ }^{30}$ all interlayer coordinates obtained from the MD simulations using Clayff were shifted $0.2 \AA$ from the clay basal plane. In general, up to four mixed phases was used in the modeling, where each mixed phase consisted of two phases of either neat Na-MMT $(9.6,12.4,15.6,18.9 \AA)$ or lactose/Na-MMT (14 and $18 \AA$ ), at different lactose and water loadings. In total 15 fitting parameters were used: the basal spacings $\left(\mathrm{d}_{001} \pm 0.2 \AA, n=3\right)$, the probability weights of each mixed phase $(\mathrm{W}, n=4)$ with its two respective individual phases $\left(\mathrm{P}_{\mathrm{A} / \mathrm{B}}\right)$, the average nanocomposite particle orientation $\left(\sigma^{*}\right)$, sample roughness, particle size $\left(\mathrm{N}_{\mathrm{ave}}\right)$ and lattice strain $(\alpha)$. For denotations and terminology see references. ${ }^{31,41}$

\section{Solid-state nuclear magnetic resonance}

${ }^{13} \mathrm{C}$ solid-state nuclear magnetic resonance (NMR) spectra were acquired using a Bruker 400 $\mathrm{MHz}$ Avance III spectrometer equipped with a triple resonance probe at frequencies $400.23 \mathrm{MHz}$ $\left({ }^{1} \mathrm{H}\right), 100.64 \mathrm{MHz}\left({ }^{13} \mathrm{C}\right) .{ }^{29} \mathrm{Si}$ solid-state NMR spectra were acquired using a Bruker $300 \mathrm{MHz}$ Avance III spectrometer with a double resonance probe at frequencies $300.13 \mathrm{MHz}\left({ }^{1} \mathrm{H}\right)$ and 59.63 $\mathrm{MHz}\left({ }^{29} \mathrm{Si}\right)$. The materials were packed to the $4 \mathrm{~mm}$ zirconia rotors and rotated at an MAS rate of $10 \mathrm{kHz}\left({ }^{13} \mathrm{C}\right)$ and $4 \mathrm{kHz}\left({ }^{29} \mathrm{Si}\right)$. All materials were characterized using ${ }^{29} \mathrm{Si}\left({ }^{29} \mathrm{Si} \pi / 2\right.$ pulse length $4.1 \mu$ s with 30 s recycle delay), ${ }^{1} \mathrm{H}_{-}{ }^{13} \mathrm{C}$ and ${ }^{1} \mathrm{H}_{-}{ }^{29} \mathrm{Si}$ cross-polarization magic angle spinning (CP/MAS) techniques $\left({ }^{13} \mathrm{C} \pi / 2\right.$ pulse length $3.5 \mu \mathrm{s},{ }^{29} \mathrm{Si} \pi / 2$ pulse length $4.5 \mu$ s with a contact time of $2 \mathrm{~ms}$, SPINAL64 decoupling was used during signal acquisition and recycle delay of $30 \mathrm{~s}$ was applied). The Hartmann-Hahn conditions for ${ }^{1} \mathrm{H}-{ }^{13} \mathrm{C}$ and ${ }^{1} \mathrm{H}-{ }^{29} \mathrm{Si} \mathrm{CP} / \mathrm{MAS}$ NMR experiments were set with hexamethylbenzene and kaolinite respectively. Typically 2048 scans were acquired for ${ }^{29} \mathrm{Si}$ and ${ }^{1} \mathrm{H}-{ }^{13} \mathrm{C}$ CP/MAS and 1024 for ${ }^{1} \mathrm{H}_{-}{ }^{29} \mathrm{Si} \mathrm{CP} / \mathrm{MAS}$ NMR 
experiments. The ${ }^{13} \mathrm{C}$ and ${ }^{29} \mathrm{Si}$ chemical shifts were recorded with respect to TMS. As lactose in crystalline and amorphous state demonstrates significantly different ${ }^{1} \mathrm{H}_{1} \mathrm{~T}_{1}$ relaxation, recycle delay for crystalline lactose monohydrate (540 s), co-spray-dried amorphous lactose (30 s), lactose/Na-MMT nanocomposites (30 s) and humidity stressed samples (180 s) was optimized in set of ${ }^{1} \mathrm{H}-{ }^{13} \mathrm{C}$ CP/MAS experiments with different delay times. These conditions allowed full relaxation of carbon atoms.

\section{Differential scanning calorimetry}

Modulated differential scanning calorimetry (mDSC) Q2000 (TA Instruments, New Castle, DE) with a refrigerated cooling system was used to determine the glass transition temperature $\left(T_{g}\right)$, glass transition temperature width (from onset to end point temperature, $\Delta T_{g}$ ) and weight normalized (per gram lactose) change in heat capacity at $T_{g}\left(\Delta C_{p}^{T g}\right)$. The mDSC was calibrated for heat flow and temperature as well as heat capacity using high purity indium and sapphire, respectively. A nitrogen flow of $50 \mathrm{ml} / \mathrm{min}$ was used as purge gas. The samples $(5-12 \mathrm{mg})$ were analyzed in triplicates using aluminum pans with pin-holed lids (TA Instruments, New Castle, $\mathrm{DE})$. The measurements were carried out at a heating rate of $1 \mathrm{~K} / \mathrm{min}$, a modulation temperature of $\pm 2 \mathrm{~K}$, and a period of 80 seconds between $373 \mathrm{~K}$ and $503 \mathrm{~K}$. This protocol also served to evaporate any residual water. The $T_{g}$ was taken as the inflection point.

\section{Investigation of structural relaxation with isothermal microcalorimetry}

A modified method described by Liu et al. ${ }^{42}$ was used to investigate of the structural relaxation ( $\alpha$-relaxation) of spray-dried neat amorphous lactose and the co-spray-dried lactose/Na-MMT nanocomposite with 63\% Na-MMT. An isothermal microcalorimeter, 2277 Thermal Activity Monitor (Thermometric AB, Järfälla, Sweden), was used to measure the rate of enthalpy 
relaxation. Sample loads equivalent to $450 \mathrm{mg}$ lactose were weighted into $3 \mathrm{~mL}$ glass ampoules for each measurement. Crystalline glycine equivalent to the lactose load and neat spray-dried NaMMT equivalent to the Na-MMT load in the sample was used as reference. The measurement was started immediately after the spray-drying to minimize the influence of the thermal history in the samples. It took less than $30 \mathrm{~min}$ from starting the spray-drying until the samples were loaded into the microcalorimeter. The samples were pre-thermostated for $30 \mathrm{~min}$, and then lowered down into the measurement position. Data was acquired for at least $100 \mathrm{~h}$. The measurements were commenced at $333 \mathrm{~K}$. Only the data after the first hour were used for evaluation due to initial disturbances of lowering the samples to the measurement position. The MSE equation expressed for heat power $P, \mu \mathrm{W} / \mathrm{g}$, with time in hours, as follows

$P=\frac{\left(T_{g}-T\right) \cdot \Delta C_{p}}{\tau_{0}}\left(1+\frac{\beta t}{\tau_{1}}\right)\left(1+\frac{t}{\tau_{1}}\right)^{\beta-2} \exp \left[-\left(\frac{t}{\tau_{0}}\right)\left(1+\frac{t}{\tau_{1}}\right)^{\beta-1}\right]$

was used to evaluate the acquired data, where $T_{g}$ is glass transition temperature determined with mDSC, $T$ is the relaxation temperature, $\Delta C_{p}$ is the change in heat capacity at the $T_{g}, t$ is the time, and $\tau_{1}, \tau_{2}$, and $\beta$ are constants. $\tau_{1}, \tau_{2}$, and $\beta$ were determined by fitting $P$ as a function of time $t$ to Equation 3. The relaxation time $\tau$ could then be calculated from $\tau_{1}, \tau_{2}$, and $\beta$, as in the following $\tau=\tau_{0}^{1 / \beta} \cdot \tau_{1}^{(\beta-1) / \beta}$

The stretched relaxation time, $\tau^{\beta}$ was reported as a value of the structural relaxation and subsequently the molecular mobility in the samples.

\section{RESULTS}

\section{Montmorillonite characteristics}

The Na-MMT suspensions had median particle size by volume of $163 \pm 75 \mathrm{~nm}$ (mean $\pm \mathrm{SEM}$ ) measured with photon correlation spectroscopy prior spray-drying. Measured with laser 
diffraction, the median particle size by volume was $418 \pm 31 \mathrm{~nm}$ (mean \pm SEM). No particles or aggregates of particles were detected with a particle size larger than $1 \mu \mathrm{m}$. The cryo-TEM indicated similar particle size for Na-MMT (Figure 1).

\section{Nanocomposite composition and morphology}

The lactose content in the co-spray-dried lactose/Na-MMT nanocomposites was determined with thermogravimetric analysis and was found to be in agreement with expected based on amount of components added during preparation (see Supporting information, Table S1). The neat spraydried lactose and the co-spray-dried nanocomposites with low Na-MMT content consisted of spherical particles (Figure 2) whereas the nanocomposite particles at high Na-MMT contents showed "raisin-like" morphology. In the humidity stressed nanocomposites, about $5 \mu \mathrm{m}$ large crystals were apparent.

\section{XRD and MD results}

No diffraction peaks that could be attributed to crystalline lactose (Figure 3) or the do01 typically found in hydrated and neat montmorillonite, could be observed in the diffractograms of the cospray-dried lactose/Na-MMT nanocomposites. ${ }^{3}$ Instead peaks representing two populations of Na-MMT with $\mathrm{d}_{001}$ at $c a .14$ or $18 \AA$ were found. The peak corresponding to a $\mathrm{d}_{001}$ at $18 \AA$ was pronounced mostly at low Na-MMT content and the peak with a d $\mathrm{d}_{001}$ at $14 \AA$ was prevalent at high Na-MMT content. To extract more detailed information of the $d_{001}$ populations and the amount of intercalated lactose in the lactose/Na-MMT nanocomposites, the dool reflections were modeled with XRD profile fitting based on MD simulations (Figure 3, Table 1). An indication to the amount of intercalated lactose was found by fitting the complete experimental data set with 12 different combinations of the 7 different $G$-factors having different lactose/water ratios and 
d001 values approximating 14 and $18 \AA$, respectively. The set of $G$-factors that led to the best fit corresponded to 120 water molecules plus 4 and 16 lactose molecules per simulation cell for the $\mathrm{d}_{001}$ at 14 and $18 \AA$ respectively, although it was necessary to include a fraction of neat Na-MMT to get a good fit. This was thus equivalent to 5 water molecules and $1 / 6$ lactose or $4 / 5$ lactose molecules, respectively, per MMT unit cell area $\left(0.467 \mathrm{~nm}^{2}\right)$. These results were independent of nanocomposite preparation conditions. Irrespective of the two sets of simulation times (100-200 ps or 250-500 ps), the corresponding MD results for these systems showed that intercalated lactose yielding a d001 of approximately $14 \AA$ was in fact formed by a lactose mono-layer, whereas a $\mathrm{d}_{001}$ of $18 \AA$ resulted from overlapping lactose molecules. Although the agreement between the $\mathrm{d}_{001}$ values versus water and lactose loading were generally good between the two simulation times, sporadic differences in the d001 values was found between the two sets of simulations at higher lactose contents due to an increasing number of occasional overlap of individual pairs of lactose molecules. Figure S7 and Figure S8 in the supporting information show the resulting $\mathrm{d}_{001}$ versus lactose and water loading data and the atomic and electron density profiles used in calculation of the final $G$-factors. It should however be stressed that the electron density in lactose and water molecules is of similar magnitude making precise estimates difficult, unless using a combination of X-ray and neutron diffraction techniques. ${ }^{30}$ In fact, due to the many fitting parameters used, reasonable good fits could also be found using $G$-factors computed with slightly different lactose/water ratios (Figure S1). Nevertheless, by comparing the interlayer space size with the results from simulations without lactose, the volume fraction of the intercalated lactose could also be estimated, assuming small and insignificant differences in the density of water and clay lattice between the simulations. In agreement with a previous study, ${ }^{39}$ simulations with only 5 water molecules per unit cell resulted in a $\mathrm{d}_{001}$ at $c a .12 .4 \AA$, equivalent 
to the first hydration state (single monolayer) of neat montmorillonite, ${ }^{3}$ and a interlayer space size of $3.1 \AA$. With $1 / 6$ lactose molecules per unit cell, the equivalent interlayer space size was found to be $4.7 \AA$, that is, $50 \%$ larger than without lactose. This suggests that the volume fraction of lactose in the interlayer corresponding to the $\mathrm{d}_{001}$ at $14 \AA$ was approximately $1 / 3$. Similarly, the equivalent volume fraction was nearly $2 / 3$ for the $18 \AA$ population.

The average basal spacing $\left(\mathrm{d}_{001, \text { Ave }}\right)$ which can be used as a measure of the relative distribution between the different populations of the nanocomposites, increased with increasing amount of lactose (Figure 3, Table 1). In the humidity stressed nanocomposites, $\mathrm{d}_{001, \text { Ave }}$ remained at about $14 \AA$ independent of composition (Table 1, Figure S2). In these samples, diffraction peaks that could be attributed to $\alpha$-lactose monohydrate were also apparent. Lactose/Na-MMT nanocomposites were also prepared by drying Na-MMT-lactose suspensions under ambient conditions to investigate whether the extent of lactose intercalation was kinetically controlled and, hence, dependent on method of preparation. Overall, the results resemble the humidity stressed nanocomposites with $\mathrm{d}_{001, \mathrm{Ave}}$ at about $14 \AA$ and diffraction peaks characteristic of $\alpha$ lactose monohydrate (Figure S2, Table 1).

\section{Solid-state NMR results}

${ }^{1} \mathrm{H}-{ }^{13} \mathrm{C}$ solid-state NMR spectra of spray-dried lactose and co-spray-dried lactose/Na-MMT nanocomposites demonstrated broad peaks characteristic of amorphous solids (Figure 4A). Increase of the Na-MMT content in the nanocomposites was followed by a decrease of the ${ }^{13} \mathrm{C}$ lactose peaks intensities. It is important to note that such a change in peaks intensities was not linear with respect to the chemical composition of the materials. 
The humidity exposure of the lactose/Na-MMT nanocomposites resulted in a significant narrowing of the peaks in the ${ }^{1} \mathrm{H}-{ }^{13} \mathrm{C}$ solid-state NMR spectra. The chemical shifts of the peaks were similar to those observed for crystalline lactose monohydrate (Figure 4B). The deviation from linearity for ${ }^{13} \mathrm{C}$ peak intensity as a function of Na-MMT content was also apparent for these crystallized nanocomposites, but this deviation was less pronounced than for the amorphous nanocomposites (Figure 4B (Inset)).

${ }^{29} \mathrm{Si}$ MAS NMR spectra of co-spray-dried lactose/Na-MMT nanocomposites displayed two peaks at -94.0 and $-109.0 \mathrm{ppm}$. The peak at $-94 \mathrm{ppm}$ can be assigned to $(\mathrm{SiO})_{3} \mathrm{Si}(\mathrm{OAl}(\mathrm{VI}))$ environment $\left(\mathrm{Q}^{3}\right.$ site $)$ in the tetrahedral sheet of the clay and it is in agreement with previously reported ${ }^{29} \mathrm{Si}$ solid-state NMR spectra of smectites. ${ }^{43-46}$ The peak at $-109.0 \mathrm{ppm}$ corresponds to $\mathrm{Q}^{4}$ site of silicon in $\alpha$-quartz, which is a common impurity in the montmorillonite clays. ${ }^{44,46} \mathrm{~A}$ decrease of the Na-MMT content within the mixture resulted in the expected, linear decrease of the ${ }^{29} \mathrm{Si}$ peaks intensity. Similarly, ${ }^{29} \mathrm{Si}$ spectra of the humidity stressed nanocomposites had two distinct ${ }^{29} \mathrm{Si}$ sites at -94.0 and $-109.0 \mathrm{ppm}$ and the same linear decrease of the ${ }^{29} \mathrm{Si}$ peaks intensities with decreasing Na-MMT content within the nanocomposite (Figure 5A and B). In contrast to ${ }^{29} \mathrm{Si}$ MAS NMR experiment, ${ }^{1} \mathrm{H}-{ }^{29} \mathrm{Si} \mathrm{CP} / \mathrm{MAS}$ NMR spectra of Na-MMT and obtained nanocomposites demonstrated only one peak at $-94.0 \mathrm{ppm}$ assigned to $(\mathrm{SiO})_{3} \mathbf{S i}(\mathrm{OAl}(\mathrm{VI}))$ environment $\left(\mathrm{Q}^{3}\right.$ site $)$.

\section{mDSC results}

Figure 6 illustrates the glass transition characteristics (see Figure S3 for the mDSC response). Only minor changes in the glass transition temperature $\left(T_{g}\right)$ were detected. The $T_{g}$ was increased for the nanocomposites with 72\% Na-MMT $(2.1 \mathrm{~K})$ and $80 \%$ Na-MMT $(3.1 \mathrm{~K})$. No other changes in $T_{g}$ were significant. Co-spray-drying of lactose with Na-MMT however led to a 
broadening of the glass transition of lactose, that is, $\Delta T_{g}$ increased with Na-MMT content, from $6.1 \mathrm{~K}$ in neat amorphous lactose to $17.6 \mathrm{~K}$ in the nanocomposite with $80 \% \mathrm{Na}-\mathrm{MMT}$. The $\Delta C_{p}{ }^{T g}$ decreased as a function of $\mathrm{Na}-\mathrm{MMT}$ content in the nanocomposites, from $0.60 \mathrm{~J} /(\mathrm{g}$ lactose $\cdot \mathrm{K})$ in neat amorphous lactose to $0.17 \mathrm{~J} /(\mathrm{g}$ lactose $\cdot \mathrm{K})$ in the nanocomposite with $80 \%$ Na-MMT. No glass transition could be detected in the humidity stressed nanocomposites.

\section{Investigation of structural relaxation with isothermal microcalorimetry}

The stretched relaxation time, $\tau^{\beta}$ for the co-spray-dried lactose/Na-MMT nanocomposite with $63 \%$ Na-MMT was significantly lower $(4.9 \pm 0.2(-))$ compared with the neat amorphous lactose $(23.3 \pm 1.5(-))$ (unpaired two-tailed t-test, $p<0.05$, see Figure S4 for the MSE equation fitted to the experimental data).

\section{DISCUSSION}

MMT platelets are less than $1 \mathrm{~nm}$ thick flat flakes with a very high aspect ratios (100-1500). ${ }^{47}$ Separate platelets form spontaneously by exfoliation when mixed with water and resume its stacked (lamellar) structure upon drying. ${ }^{48,49}$ The analysis of the particle size of the Na-MMT dispersions with laser diffraction, photon correlation spectroscopy and cryo-TEM revealed no larger aggregates; the platelets were exfoliated when dispersed in the water.

\section{Intercalation of lactose}

The observed atypical basal spacing ( $\left.\mathrm{d}_{001}\right)$ of the lactose/Na-MMT nanocomposites, approximating the size of lactose molecules strongly indicate that lactose was intercalated between the Na-MMT sheets when Na-MMT was co-spray-dried with lactose. The MD simulations in combination with XRD profile fittings support this finding, since it was required to have a $G$-factor with significant amounts of lactose to achieve satisfactory agreement between 
the experimental and modeled XRD patterns. Intercalation of lactose in Na-MMT is not unexpected since the lactose is very hydrophilic and has hydroxyl groups which can interact with the charged surfaces and counter-ions in between the MMT sheets. ${ }^{50}$ The XRD data demonstrate that the Na-MMT with intercalated lactose appear as of two coexisting populations, one with $\mathrm{d}_{001}$ at $c a .14 \AA$ and the other at $c a .18 \AA$. The mass fraction of one population, relative to the other, varies with composition. This means that the increase in $\mathrm{d}_{001}$ of the Na-MMT occurs in two steps, each at about $4 \AA$ when increasing the mass fraction of lactose in the nanocomposite.

The size of lactose molecules can be estimated from the size of the unit cell of crystalline lactose and from wrapping box calculations implemented in $\mathrm{Olex}^{2}$ crystallographic software. The dimensions of the lactose unit cell ranges from 4.8 to $21.6 \AA$ depending on orientation and which polymorphic modification is considered..$^{51-53}$ The wrapping box calculations yielded a smallest dimension of the lactose molecule of $6.5 \AA$. The thickness of the MMT sheets can be estimated to $9.3 \AA$ from the mineral pyrophyllite, which has the same basic structure as MMT but without anything intercalated, due to lack of isomorphous substitution. ${ }^{54}$ Thus, the observed increase in $\mathrm{d}_{001}$ is in the lower end of the smallest dimension of the lactose molecule, which indicates that the lactose molecules lay flat in the Na-MMT interlayer space. This is in agreement with previously described results for intercalation of 5-fluorouracil, ${ }^{9}$ oxytetracycline, ${ }^{12,13}$ and timolol maleate $^{7}$ in MMT.

Kevadiya et $a l .{ }^{9}$ reported that the $\mathrm{d}_{001}$ increased in two approximately equal steps at increasing loading of 5-fluorouracil and chitosan in MMT. It was speculated that the enlarged $\mathrm{d}_{001}$ indicates a double layer of intercalated chitosan in MMT. Double layer conformations have also been suggested for aliphatic ammonium bentonite complexes. ${ }^{55-57}$ In the present study, the MD simulations on the nanocomposites with lactose and Na-MMT indicated that the lactose 
molecules are partly overlapping in the nanocomposites at high loadings of lactose (Figure S8). Therefore, the population with $\mathrm{d}_{001}$ at $14 \AA$ represent monolayer configuration of intercalated lactose, whereas the population with $\mathrm{d}_{001}$ at $18 \AA$ most likely represents a partially overlapping configuration of the intercalated lactose in the Na-MMT.

The $\mathrm{d}_{001}$ decreased in the nanocomposites with low Na-MMT content from 18 to $14 \AA$ upon humidity stress of the nanocomposites. The decreased rate of drying at ambient conditions also led to nanocomposites with $\mathrm{d}_{001}$, Ave of approximate $14 \AA$. The intensity of ${ }^{1} \mathrm{H}-{ }^{13} \mathrm{C}$ CP NMR peaks from the intercalated lactose was lower in the co-spray-dried nanocomposites that were stored over silica gel compared with the humidity stressed nanocomposites. This indicates a higher degree of intercalated lactose in these nanocomposites since more lactose molecules could be in close proximity (up to $1 \mathrm{~nm}$ ) to the paramagnetic center or have increased mobility in comparison with lactose species in the humidity stressed nanocomposites.

The MD simulations in combination with XRD profile fittings can be used as a semiquantitative measure of the amount intercalated lactose. In the samples with a d d 001 at $14 \AA$, the simulations indicated that approximate 1/6 lactose molecules per MMT unit cell, but significant higher amounts of lactose in the samples with a $d_{001}$ at $18 \AA$, that is, approximate $4 / 5$ lactose molecules per MMT unit cell. Thus, the lowered $\mathrm{d}_{001}$ from 18 to $14 \AA$ in the humidity stressed nanocomposites with low Na-MMT content combined with the differences in ${ }^{1} \mathrm{H}-{ }^{13} \mathrm{C}$ CP NMR peaks signal intensities clearly demonstrate diffusion of intercalated lactose out from the $\mathrm{Na}$ MMT interlayer space.

The diffusion of intercalated lactose molecules to the non-intercalated phase in the humidity stressed nanocomposites was further confirmed by ${ }^{1} \mathrm{H}_{-}{ }^{29} \mathrm{Si} \mathrm{CP} / \mathrm{MAS}$ solid-state NMR spectra of the nanocomposites. As the signal intensity in CP/MAS experiment depends on the transfer of 
magnetization from highly abundant nuclei $\left({ }^{1} \mathrm{H}\right)$ to low abundant nuclei $\left({ }^{29} \mathrm{Si}\right)$ through dipolar interactions, the peak at $-94.0 \mathrm{ppm}$ can obtain magnetization from both structural hydrogen in the clay and dispersed lactose molecules in close proximity to the ${ }^{29} \mathrm{Si}$ nuclei.

An ideal behavior of the ${ }^{1} \mathrm{H}^{29} \mathrm{Si} \mathrm{CP} / \mathrm{MAS}$ spectra of the nanocomposites would be a gradual decrease of the peaks intensity as the Na-MMT content in the nanocomposites decreases. Interestingly, the intensity of the peak at $-94.0 \mathrm{ppm}$ was constant irrespectively of Na-MMT content (Figure 5C). This observation could be due to the fact that in the co-spray-dried nanocomposites lactose species located in the interlayer space of the nanocomposites become the dominant source of ${ }^{1} \mathrm{H}$ sites contributing to $\mathrm{CP}$ transfer to ${ }^{29} \mathrm{Si}$ nuclei. Since such nanocomposites show a considerable population of the phase with $d_{001}$ at $18 \AA$ and an increased amount of intercalated lactose, the deviation from the ideal trend of the intensity of ${ }^{1} \mathrm{H}^{2}{ }^{29} \mathrm{Si} \mathrm{CP} / \mathrm{MAS}$ spectra reflect a higher population of ${ }^{1} \mathrm{H}$ sites contributing to cross polarization.

The ${ }^{1} \mathrm{H}^{29} \mathrm{Si} \mathrm{CP} / \mathrm{MAS}$ spectra of humidity stressed nanocomposites show an ideal behavior, that is, a linear decrease of the ${ }^{29} \mathrm{Si}$ peak intensity with decreasing Na-MMT content within the nanocomposites. This indicates partial separation of lactose molecules from clay particles followed by its recrystallization and formation of lactose monohydrate as confirmed by XRD, solid-state NMR and scanning electron microscopy (Figure 4B and Figure S2). In summary, lactose has an affinity to be intercalated as a monolayer in between the Na-MMT layers, and the nanocomposites are kinetically trapped with a $\mathrm{d}_{001}$ at $18 \AA$ at the rapid evaporation during the cospray-drying.

\section{Domains of non-intercalated lactose}

The detection of a $T_{g}$ confirms that a neat amorphous lactose phase is present in the lactose/NaMMT nanocomposites. Domains of non-intercalated lactose are expected when the amount of 
added lactose exceeds the amount that can be intercalated in the interlayer space. Assuming thermodynamic equilibrium, the neat lactose phase would be absent at compositions below a critical composition where all interlayer space have been filled and a linear increase of nonintercalated lactose above this critical point (that is, the solubility of lactose in Na-MMT).

The decrease of the $\Delta C_{p}{ }^{T g}$ as a function of Na-MMT content (Figure 6) is due to a decrease in the fraction of the lactose that is contributing to the magnitude of $\Delta C_{p}{ }^{T g}$. Similar observations have been demonstrated in nanocomposites with silica or carbon nanotubes as fillers. ${ }^{27,}{ }^{58-61}$ Assuming that the intercalated lactose is the fraction that not contributes to the magnitude of $\Delta C_{p}{ }^{T g}$, the fractions of the lactose being intercalated lactose and non-intercalated as a function of composition can be semi-quantitatively calculated. This is corroborated by a loss of ${ }^{1} \mathrm{H}-{ }^{13} \mathrm{C}$ CP/MAS solid-state NMR signal intensity in the nanocomposites compared with what could be expected from simple physical mixtures of the lactose and Na-MMT. Overall, the plot in Figure 7 follows the assumed phase behavior for the co-spray-dried nanocomposites with a decreasing non-intercalated lactose fraction at increasing Na-MMT content in the nanocomposites, and both methods confirm presence of non-intercalated lactose even at high Na-MMT content. Interestingly, non-intercalated lactose is also present in the co-spray-dried nanocomposites with as high as $80 \%$ Na-MMT content, in which all the lactose present was expected to be intercalated.

It is important to note that the signal intensity in CP/MAS NMR experiments depends on the efficiency of magnetization transfer from high abundance to low abundance nuclei, which in turn is affected by the local atom environment. In high mobility regimes, magnetization transfer during $\mathrm{CP}$ step may not be efficient, leading to a loss of the ${ }^{13} \mathrm{C}$ NMR signal intensity. ${ }^{62}$ It is known that nanoconfined/surface molecules demonstrate increased mobility that may lead to loss 
of CP signal. ${ }^{22,63-66}$ Furthermore, the decreased signal intensity in the CP/MAS experiment can be related partially to the paramagnetic impurities present in the naturally sourced clay, that is, $2.9 \mathrm{wt} \%$ of the $\mathrm{Fe}(\mathrm{III})$ ions. ${ }^{67}$ The substantial decrease in the longitudinal $\left(\mathrm{T}_{1}\right)$ relaxation times due to contribution from electron-nuclear spin relaxation mechanism led to an overall decrease of the signal intensity. Reduction of the ${ }^{13} \mathrm{C}$ and ${ }^{1} \mathrm{H}$ signal intensity together with peak broadening due to the presence of paramagnetic species have previously been reported for polymer/MMT nanocomposites. ${ }^{68,69}$ It is known that paramagnetic interactions from Fe(III) ions mostly located at the surface of the clay sheets may perturb the observable signal from the nuclei which are in $1 \mathrm{~nm}$ distance from the paramagnetic center. ${ }^{68,69}$ VanderHart et al. ${ }^{70}$ used changes in the ${ }^{1} \mathrm{H} \mathrm{T}_{1}$ relaxation times induced by paramagnetic species as one of the indicators of uniform dispersion of MMT in the polymer-clay nanocomposites. Thus, the non-linear decrease in the ${ }^{1} \mathrm{H}-{ }^{13} \mathrm{C}$ solid-state NMR intensities of the nanocomposites can be explained by both these phenomena.

The molecular mobility of the non-intercalated lactose in the co-spray-dried nanocomposites was estimated with structural relaxation studies conducted with microcalorimetry. Structural relaxation ( $\alpha$-relaxation) reflects motion of the whole molecule, such as diffusional motion and viscous flow. ${ }^{71,72}$ The structural relaxation time, $\tau^{\beta}$ is reverse proportional to the molecular mobility. Thus, the lowered $\tau^{\beta}$ in the nanocomposite demonstrate an increase of the molecular mobility of the amorphous lactose phase in the nanocomposites compared with neat amorphous lactose, also in agreement with the interpretation of solid-state NMR data above.

The glass transition width, $\Delta T_{g}$, was increased with increasing Na-MMT content (see Figure 6), which can be interpreted as heterogeneity in the non-intercalated amorphous lactose phase, since the relaxation of the amorphous domains can take place on slightly different time scales. ${ }^{73}$, 
${ }^{74}$ This may indicate the non-intercalated lactose consists of a large number of local environments with slightly different dynamic properties. ${ }^{73,74}$ There are two contributions to the heterogeneity of the amorphous non-intercalated lactose. The $T_{g}$ is a bulk phase property reflecting the molecular mobility of the amorphous phase, but molecules near surfaces may show significantly different mobility, ${ }^{75}$ either increased ${ }^{76}$ or decreased. ${ }^{77}$ Thus, the increased solid surface to lactose phase ratio when increasing the Na-MMT component in the nanocomposite may increase the $\Delta T_{g}$. Also, varying size of the domains with non-intercalated lactose, which at low lactose fractions can be considerably small, can also contribute. ${ }^{78}$

The humidity stress of the nanocomposites resulted in recrystallization of the non-intercalated lactose where relatively large lactose crystals formed (Figure 2 and Figure S2). Most likely, these crystals also consisted of lactose that diffused out of the intercalated phase upon the humidity exposure as well as recrystallized amorphous lactose domains.

\section{SUMMARY AND CONCLUSIONS}

MMT can be utilized in drug delivery applications due to its layered structure and extremely high surface area which enable intercalation of other substances. ${ }^{7-18}$ In this study, we demonstrated that co-spray-drying of lactose and Na-MMT leads to lactose intercalation, showing that an uncharged organic compound may intercalate in interlayer space of the nanoclay. It can be assumed that the hydrogen bonding capacity of the lactose plays an important role for interaction with clay surfaces.

The intercalated lactose either formed a monolayer or partially overlapping layers in the NaMMT, resulting in stacks with a basal spacing, $\mathrm{d}_{001}$ at 14 or $18 \AA$, respectively. The degree of intercalation was dependent on nanocomposite preparation conditions, that is, the drying rate. This implicates that during fast drying, as provided by spray-drying, the dissolved lactose can be 
trapped in between clay layers during dehydration. Thus, the formation of lactose-intercalated stacks of Na-MMT with $\mathrm{d}_{001}$ at $18 \AA$ is kinetically controlled. This was supported by the increased tendency to form $18 \AA$ stacks upon increasing the lactose content in the nanocomposites. However, at slow drying preferentially stacks with $\mathrm{d}_{001}$ at $14 \AA$ were formed, indicating that the intercalation resulting in monolayer intercalation was thermodynamically driven. This was further supported by the observation that the system formed $14 \AA$ stacks upon humidity exposure, whereas the $18 \AA$ stacks thereby where eliminated. Importantly, stacks of Na-MMT intercalated with lactose giving $\mathrm{d}_{001}$ at $14 \AA$ remained despite recrystallization of the lactose upon storage in high humidity.

The presence of non-intercalated organic domains and the size of these domains may affect the physical stability and the hygroscopicity of amorphous pharmaceutical nanocomposites with MMT as the nanofiller. Interestingly, even at high Na-MMT content (up to $c a .90 \%$ Na-MMT) domains of non-intercalated lactose were detected. This indicates on the approximate quantity of organic compounds that are possible to formulate in amorphous pharmaceutical nanocomposites with Na-MMT to achieve long-term stability. The presence of non-intercalated lactose at this NaMMT content is also an indication of possible difficulties in loading high weight fractions of nonionic organic substances into Na-MMT without forming pure organic domains, despite having high drying rate. From the drug delivery perspective it is important to emphasize that drug rich domains may potentially influence the release profile by imposing rapid initial release before a sustained release of intercalated drug can be achieved.

In summary, we conclude that the investigated nanocomposites consist of lactose-intercalated Na-MMT tactoids, in an intimate mix with a non-intercalated lactose phase. The molecular mobility of the lactose in the nanocomposites is more heterogeneous and generally higher than in 
neat amorphous lactose due to the interfacial interactions between lactose and Na-MMT surfaces. This study provides a basis for understanding pharmaceutically relevant properties of MMT nanocomposites, such as loading capacity of the clay and the physical stability of the system.

\section{TABLES}

Table 1. Basal spacing (d) and total fraction $(\mathrm{P})$ of the modeled basal spacing populations of nanocomposites prepared by co-spray-drying, humidity stressed nanocomposites (co-spray-dried lactose/Na-MMT that were stored in 94\% relative humidity (RH) followed by drying), and nanocomposites prepared under ambient conditions. The subscripts denote the start value of the modelling. 


\begin{tabular}{|c|c|c|c|c|c|c|c|c|c|c|c|}
\hline & $\begin{array}{l}\text { Na-MMT } \\
\text { content }(\%)\end{array}$ & d9.6 & $d_{12.4}$ & $d_{14}$ & $d_{18}$ & $\mathbf{P}_{9.6}$ & $\mathbf{P}_{12.4}$ & $\mathbf{P}_{14}$ & $\mathbf{P}_{18}$ & d001, Ave & do01, Bragg \\
\hline & $20 \%$ & - & 12.2 & 13.8 & 18.0 & - & 0.00 & 0.26 & 0.74 & 16.9 & 18.2 \\
\hline & $42 \%$ & - & 12.3 & 14.2 & 18.0 & - & 0.00 & 0.13 & 0.87 & 17.5 & 18.2 \\
\hline \multirow{6}{*}{ 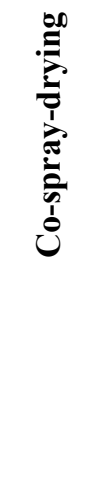 } & $63 \%$ & - & 12.2 & 14.2 & 18.1 & - & 0.03 & 0.27 & 0.70 & 16.9 & 18.2 \\
\hline & $72 \%$ & - & 12.6 & 14.2 & 18.0 & - & 0.08 & 0.50 & 0.42 & 15.7 & 18.2 \\
\hline & $80 \%$ & - & 12.4 & 14.0 & 18.2 & - & 0.10 & 0.76 & 0.14 & 14.4 & 14.1 \\
\hline & $90 \%$ & 9.7 & 12.4 & 14.0 & - & 0.33 & 0.29 & 0.38 & - & 12.1 & 14.1 \\
\hline & $100 \%$ & 9.7 & 12.5 & - & - & 0.87 & 0.13 & - & - & 10.0 & 10.4 \\
\hline & $\begin{array}{l}\text { Na-MMT } \\
\text { content }(\%)\end{array}$ & d9.6 & $d_{12.4}$ & $d_{14}$ & $d_{18}$ & $\mathbf{P}_{9.6}$ & $P_{12.4}$ & $\mathbf{P}_{14}$ & $\mathbf{P}_{18}$ & d001, Ave & d001, Bragg \\
\hline \multirow{8}{*}{ 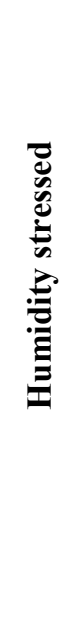 } & $20 \%$ & - & 12.6 & 14.1 & 18.2 & - & 0.29 & 0.64 & 0.07 & 13.9 & 13.7 \\
\hline & $42 \%$ & - & 12.6 & 14.0 & 18.1 & - & 0.21 & 0.69 & 0.10 & 14.1 & 13.7 \\
\hline & $63 \%$ & - & 12.4 & 13.9 & 18.0 & - & 0.02 & 0.97 & 0.01 & 13.9 & 14.2 \\
\hline & $72 \%$ & - & 12.5 & 14.0 & 18.0 & - & 0.14 & 0.82 & 0.04 & 13.9 & 13.9 \\
\hline & $80 \%$ & - & 12.5 & 14.0 & 18.0 & - & 0.20 & 0.76 & 0.04 & 13.9 & 13.8 \\
\hline & $90 \%$ & - & 12.6 & 14.0 & 18.1 & - & 0.25 & 0.68 & 0.07 & 13.9 & 13.9 \\
\hline & $100 \%$ & 9.6 & 12.4 & - & - & 0.74 & 0.26 & - & - & 10.3 & 11.1 \\
\hline & $\begin{array}{l}\text { Na-MMT } \\
\text { content (\%) }\end{array}$ & d9.6 & $\mathrm{d}_{12.4}$ & $d_{14}$ & $d_{18}$ & P9.6 & $P_{12.4}$ & $\mathbf{P}_{14}$ & $\mathbf{P}_{18}$ & d001, Ave & d001, Bragg \\
\hline \multirow{6}{*}{ 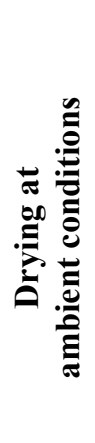 } & $20 \%$ & - & 12.6 & 14.2 & 18.3 & - & 0.22 & 0.62 & 0.16 & 14.5 & 13.8 \\
\hline & $42 \%$ & - & 12.6 & 14.2 & 18.0 & - & 0.20 & 0.65 & 0.15 & 14.4 & 13.8 \\
\hline & $63 \%$ & - & 12.6 & 14.0 & 18.2 & - & 0.23 & 0.67 & 0.11 & 14.1 & 13.9 \\
\hline & $72 \%$ & - & 12.2 & 14.2 & 18.0 & - & 0.06 & 0.47 & 0.48 & 15.9 & 17.9 \\
\hline & $80 \%$ & - & 12.6 & 14.2 & 18.2 & - & 0.14 & 0.61 & 0.25 & 15.0 & 14.1 \\
\hline & $100 \%$ & 9.7 & 12.5 & - & - & 0.57 & 0.43 & - & - & 10.9 & 11.6 \\
\hline
\end{tabular}




\section{ASSOCIATED CONTENT}

\section{Supporting Information.}

Normalized experimental XRD profiles for lactose/sodium montmorillonite nanocomposites of two samples representing samples with basal spacing $\left(\mathrm{d}_{001}\right)$ at approximate $14 \AA$ or $18 \AA$ with models based on different $G$-factors representing varying lactose content

Normalized experimental XRD profiles of for lactose/sodium montmorillonite of nanocomposites dried under ambient conditions, and humidity stressed nanocomposites

Estimation of populations of lactose in different environments in the lactose/Na-MMT nanocomposites with solid-state NMR

$\mathrm{mDSC}$ response for the co-spray-dried lactose/sodium montmorillonite nanocomposites

Isothermal microcalorimetry heat flow during enthalpy relaxation

Thermogravimetric analysis of lactose mass content

Content of lactose in the co-spray-dried lactose/sodium montmorillonite nanocomposites quantified using thermogravimetric analysis

TGA of lactose monohydrate and Na-MMT in nitrogen and air atmosphere

Comparison of the initial and the simulated lactose structure.

Clay basal spacing versus number of lactose molecules per simulation cell

Atomic and electron density profiles (per full composite unit cell) 
References

This material is available free of charge via the Internet at http://pubs.acs.org.

AUTHOR INFORMATION

Corresponding Author

* Denny Mahlin, Box 580, SE-751 23 Uppsala, Sweden

Phone: +46(0)18 4714662

Fax: $+46(0) 184714377$

Email: denny.mahlin@farmaci.uu.se

\section{Author Contributions}

The manuscript was written through contributions of all authors. All authors have given approval to the final version of the manuscript.

\section{Funding Sources}

Any funds used to support the research of the manuscript should be placed here (per journal style).

Notes

Any additional relevant notes should be placed here.

\section{ACKNOWLEDGMENT}

Jonny Eriksson, Department of Chemistry, Uppsala University, Sweden, captured the cryo-TEM image and Göran Ocklind, Department of Pharmacy, Uppsala University, Sweden, improved the cryo-TEM image quality. Lucia Lazorova, Department of Pharmacy, Uppsala University, 
captured the scanning electron images. KPN would like to acknowledge University of East Anglia for Postgraduate Scholarship. The simulations were performed on resources provided by the Swedish National Infrastructure for Computing (SNIC), and specifically PDC (Lindgren) and HPC2N (Abisko).

\section{ABBREVIATIONS}

CP/MAS, cross-polarization magic angle spinning; cryo-TEM, cryogenic-transmission electron microscopy; $\Delta C_{p}^{T g}$, weight normalized (per gram lactose) change in heat capacity at the glass transition temperature; $\mathrm{d}_{001}$, basal spacing; $\mathrm{d}_{001, \text { Ave }}$, average basal spacing; MD, molecular dynamic simulations, mDSC, modulated differential scanning calorimetry; MMT, montmorillonite; Na-MMT, sodium montmorillonite; $\mathrm{N}_{\text {ave }}$, particle size, NMR, nuclear magnetic resonance; $\mathrm{P}_{\mathrm{A} / \mathrm{B}}$, individual phases; $\mathrm{RH}$, relative humidity; $\mathrm{SEM}$, standard error of the mean; $T_{g}$, glass transition temperature; $\Delta T_{g}$, glass transition temperature width; $\mathrm{W}$, probability weights of each mixed phase; XRD, X-ray diffraction; $\alpha$, lattice strain; $\sigma^{*}$, average nanocomposite particle orientation

\section{REFERENCES}

1. Liu, P., Polymer modified clay minerals: A review. Appl. Clay Sci. 2007, 38 (1-2), 64-76.

2. $\quad$ Bergaya, F.; Lagaly, G., Handbook of clay science. Newnes: 2013; Vol. 5.

3. Holmboe, M.; Wold, S.; Jonsson, M., Porosity investigation of compacted bentonite using XRD profile modeling. J. Contam. Hydrol. 2012, 128 (1-4), 19-32. 
4. Marshall, C., Layer lattices and the base-exchange clays. Z. Kristallogr. 1935, 91 (1), 433-449.

5. Sinha Ray, S.; Okamoto, M., Polymer/layered silicate nanocomposites: a review from preparation to processing. Prog. Polym. Sci. 2003, 28 (11), 1539-1641.

6. Viseras, C.; Cerezo, P.; Sanchez, R.; Salcedo, I.; Aguzzi, C., Current challenges in clay minerals for drug delivery. Appl. Clay Sci. 2010, 48 (3), 291-295.

7. Joshi, G. V.; Kevadiya, B. D.; Patel, H. A.; Bajaj, H. C.; Jasra, R. V., Montmorillonite as a drug delivery system: Intercalation and in vitro release of timolol maleate. Int. J. Pharm. 2009, 374 (1-2), 53-57.

8. Iliescu, R. I.; Andronescu, E.; Ghitulica, C. D.; Voicu, G.; Ficai, A.; Hoteteu, M., Montmorillonite-alginate nanocomposite as a drug delivery system - incorporation and in vitro release of irinotecan. Int. J. Pharm. 2014, 463 (2), 184-192.

9. Kevadiya, B. D.; Patel, T. A.; Jhala, D. D.; Thumbar, R. P.; Brahmbhatt, H.; Pandya, M. P.; Rajkumar, S.; Jena, P. K.; Joshi, G. V.; Gadhia, P. K.; Tripathi, C. B.; Bajaj, H. C., Layered inorganic nanocomposites: A promising carrier for 5-fluorouracil (5-FU). Eur. J. Pharm. Biopharm. 2012, 81 (1), 91-101.

10. Iliescu, R. I.; Andronescu, E.; Voicu, G.; Ficai, A.; Covaliu, C. I., Hybrid materials based on montmorillonite and citostatic drugs: Preparation and characterization. Appl. Clay Sci. 2011, $52(1-2), 62-68$.

11. Ambrogi, V.; Nocchetti, M.; Latterini, L., Promethazine-Montmorillonite Inclusion Complex To Enhance Drug Photostability. Langmuir 2014, 30 (48), 14612-14620. 
12. Aristilde, L.; Lanson, B.; Charlet, L., Interstratification Patterns from the $\mathrm{pH}-$ Dependent Intercalation of a Tetracycline Antibiotic within Montmorillonite Layers. Langmuir 2013, 29, 4492-4501.

13. Aristilde, L.; Lanson, B.; Miéhé-Brendlé, J.; Marichal, C.; Charlet, L., Enhanced interlayer trapping of a tetracycline antibiotic within montmorillonite layers in the presence of Ca and Mg. J. Colloid Interface Sci. 2016, 464, 153-159.

14. Block, K. A.; Trusiak, A.; Katz, A.; Alimova, A.; Wei, H.; Gottlieb, P.; Steiner, J. C., Exfoliation and intercalation of montmorillonite by small peptides. Appl. Clay Sci. 2015, 107, 173-181.

15. McGinity, J. W.; Lach, J. L., In vitro adsorption of various pharmaceuticals to montmorillonite. J. Pharm. Sci. 1976, 65 (6), 896-902.

16. Su, K. S. E.; Thurøcarstensen, J., Nature of bonding in montmorillonite adsorbates II: Bonding as an ion-dipole interaction. J. Pharm. Sci. 1972, 61 (3), 420-424.

17. Thurø Carstensen, J.; Su, K. S. E., Nature of Bonding in Montmorillonite Adsorbates I:Surface Adsorption. J. Pharm. Sci. 60 (5), 733-735.

18. Peng, X.; Wang, J.; Fan, B.; Luan, Z., Sorption of endrin to montmorillonite and kaolinite clays. J. Hazard. Mater. 2009, 168 (1), 210-214.

19. Aristilde, L.; Marichal, C.; Miéhé-Brendlé, J.; Lanson, B.; Charlet, L., Interactions of Oxytetracycline with a Smectite Clay: A Spectroscopic Study with Molecular Simulations. Environ. Sci. Technol. 2010, 44 (20), 7839-7845. 
20. Lerk, C. F., Consolidation and compaction of lactose. Drug Dev. Ind. Pharm. 1993, 19 (17-18), 2359-2398.

21. Chang, L.; Shepherd, D.; Sun, J.; Ouellette, D.; Grant, K. L.; Tang, X.; Pikal, M. J., Mechanism of protein stabilization by sugars during freeze-drying and storage: Native structure preservation, specific interaction, and/or immobilization in a glassy matrix? J. Pharm. Sci. 2005, 94 (7), 1427-1444.

22. Nartowski, K.; Tedder, J.; Braun, D.; Fábián, L.; Khimyak, Y., Building solids inside nano-space: from confined amorphous through confined solvate to confined 'metastable'polymorph. Phys. Chem. Chem. Phys. 2015, 17 (38), 24761-24773.

23. Mallick, S.; Pattnaik, S.; Swain, K.; De, P. K.; Saha, A.; Ghoshal, G.; Mondal, A., Formation of physically stable amorphous phase of ibuprofen by solid state milling with kaolin. Eur. J. Pharm. Biopharm. 2008, 68 (2), 346-351.

24. Wang, L.; Cui, F. D.; Sunada, H., Preparation and Evaluation of Solid Dispersions of Nitrendipine Prepared with Fine Silica Particles Using the Melt-Mixing Method. Chem. Pharm. Bull. 2006, 54 (1), 37-43.

25. Nakahashi, T.; Matsumoto, T.; Wakiyama, N.; Moribe, K.; Yamamoto, K., The role of light anhydrous silicic acid on physical stability of troglitazone solid dispersion under humidified conditions. Adv. Powder Technol. 2014, 25 (2), 716-721.

26. Hellrup, J.; Mahlin, D., Pharmaceutical micro-particles give amorphous sucrose higher physical stability. Int. J. Pharm. 2011, 409 (1-2), 96-103. 
27. Hellrup, J.; Alderborn, G.; Mahlin, D., Inhibition of Recrystallization of Amorphous Lactose in Nanocomposites Formed by Spray-Drying. J. Pharm. Sci. 2015, 104 (11), $3760-9$.

28. Bodvik, R.; Karlson, L.; Edwards, K.; Eriksson, J.; Thormann, E.; Claesson, P. M., Aggregation of Modified Celluloses in Aqueous Solution: Transition from Methylcellulose to Hydroxypropylmethylcellulose Solution Properties Induced by a Low-Molecular-Weight Oxyethylene Additive. Langmuir 2012, 28 (38), 13562-13569.

29. Plimpton, S., Fast parallel algorithms for short-range molecular dynamics. $J$. Comput. Phys. 1995, 117, 1-42.

30. Ferrage, E.; Sakharov, B. A.; Michot, L. J.; Delville, A.; Bauer, A.; Lanson, B.; Grangeon, S.; Frapper, G.; Jimenez-Ruiz, M.; Cuello, G. J., Hydration Properties and Interlayer Organization of Water and Ions in Synthetic Na-Smectite with Tetrahedral Layer Charge. Part 2. Toward a Precise Coupling between Molecular Simulations and Diffraction Data. J. Phys. Chem. C 2011, 115, 1867-1881.

31. Moore, D. M.; Reynolds, R. C., X-Ray Diffraction and the Identification and analysis of clay minerals. 1997, 322 .

32. Jo, S.; Kim, T.; Iyer, V. G.; Im, W., CHARMM-GUI: A web-based graphical user interface for CHARMM. J. Comput. Chem. 2008, 29 (11), 1859-1865.

33. Berend, I.; Cases, J. M.; Francois, M.; Uriot, J. P.; Michot, L.; Masion, A.; Thomas, F., Mechanism of Adsorption and Desorption of Water-Vapor by Homoionic 
Montmorillonites .2. The $\mathrm{Li}+, \mathrm{Na}+, \mathrm{K}+, \mathrm{Rb}+$ and $\mathrm{Cs}+$-Exchanged Forms. Clays Clay Miner. 1995, 43 (3), 324-336.

34. Guvench, O.; Mallajosyula, S. S.; Raman, E. P.; Hatcher, E.; Vanommeslaeghe, K.; Foster, T. J.; Jamison, F. W.; MacKerell, A. D., CHARMM Additive All-Atom Force Field for Carbohydrate Derivatives and Its Utility in Polysaccharide and Carbohydrate-Protein Modeling. J. Chem. Theory Comput. 2011, 7 (10), 3162-3180.

35. Bickmore, B. R.; Rosso, K. M.; Nagy, K. L.; Cygan, R. T.; Tadanier, C. J., $A b$ initio determination of edge surface structures for dioctahedral 2:1 phyllosilicates: implications for acid-base for reactivity. Clays Clay Miner. 2003, 51 (4), 359-371.

36. Cygan, R. T.; Liang, J. J.; Kalinichev, A. G., Molecular models of hydroxide, oxyhydroxide, and clay phases and the development of a general force field. J. Phys. Chem. B 2004, 108, 1255-1266.

37. Berendsen, H. J. C.; Grigera, J. R.; Straatsma, T. P., The missing term in effective pair potentials. J. Phys. Chem. 1987, 91, 6269-6271.

38. Joung, I. S.; Cheatham, T. E., Determination of Alkali and Halide Monovalent Ion Parameters for Use in Explicitly Solvated Biomolecular Simulations. The Journal of Physical Chemistry B 2008, 112 (30), 9020-9041.

39. Holmboe, M.; Bourg, I. C., Molecular dynamics simulations of water and sodium diffusion in smectite interlayer nanopores as a function of pore size and temperature. J. Phys. Chem. C 2014, 118, 1001-1013. 
40. Reynolds, R. C., Newmod, a Computer Program for the Calculation of OneDimensional Diffraction Patterns of Mixed-Layered Clays. 8 Brook Road, Hanover, NH, 03755., 1985.

41. Snyder, R.; Bish, D., Modern powder diffraction. Rev. Mineral. 1989, 20, 101-144.

42. Liu, J.; Rigsbee, D. R.; Stotz, C.; Pikal, M. J., Dynamics of pharmaceutical amorphous solids: The study of enthalpy relaxation by isothermal microcalorimetry. J. Pharm. Sci. 2002, 91 (8), 1853-1862.

43. Kooli, F.; Khimyak, Y. Z.; Alshahateet, S. F.; Chen, F., Effect of the Acid Activation Levels of Montmorillonite Clay on the Cetyltrimethylammonium Cations Adsorption. Langmuir 2005, 21 (19), 8717-8723.

44. Guarino, A. W. S.; Gil, R. A. S. S.; Polivanov, H.; Menezes, S. M. C., Characterization of a brazilian smectite by solid state NMR and X-ray diffraction techniques. $J$. Braz. Chem. Soc. 1997, 8, 581-586.

45. Kinsey, R. A.; Kirkpatrick, R. J.; Hower, J.; Smith, K. A.; Oldfield, E., High resolution aluminum-27 and silicon-29 nuclear magnetic resonance spectroscopic study of layer silicates, including clay minerals. Am. Mineral. 1985, 70 (5-6), 537-548.

46. Dubbin, W. E.; Goh, T. B., Solid-state 27 Al and 29 Si NMR analysis of hydroxyCr and -Al interlayered montmorillonite. Clay Miner. 1997, 32 (3), 485-492.

47. Ganguly, S.; Dana, K.; Mukhopadhyay, T. K.; Parya, T. K.; Ghatak, S., Organophilic Nano Clay: A Comprehensive Review. Trans. Indian Ceram. Soc. 2011, 70 (4), 189-206. 
48. Cases, J. M.; Berend, I.; Besson, G.; Francois, M.; Uriot, J. P.; Thomas, F.; Poirier, J. E., Mechanism of adsorption and desorption of water vapor by homoionic montmorillonite. 1 . The sodium-exchanged form. Langmuir 1992, 8 (11), 2730-2739.

49. Norrish, K., The swelling of montmorillonite. Discuss. Faraday Soc. 1954, 18 (0), $120-134$.

50. Bradley, W. F., Molecular Associations between Montmorillonite and Some Polyfunctional Organic Liquids1. J. Am. Chem. Soc. 1945, 67 (6), 975-981.

51. Garnier, S.; Petit, S.; Coquerel, G., Dehydration Mechanism and Crystallisation Behaviour of Lactose. J. Therm. Anal. Calorim. 2002, 68 (2), 489-502.

52. Guiry, K. P.; Coles, S. J.; Moynihan, H. A.; Lawrence, S. E., Effect of 1-Deoxy-dlactose upon the Crystallization of d-Lactose. Cryst. Growth Des. 2008, 8 (11), 3927-3934.

53. Schreyer, M.; Guo, L.; Thirunahari, S.; Gao, F.; Garland, M., Simultaneous determination of several crystal structures from powder mixtures: the combination of powder Xray diffraction, band-target entropy minimization and Rietveld methods. J. Appl. Crystallogr. 2014, 47 (2), 659-667.

54. Brown, G.; Brindley, G. W., Crystal structures of clay minerals and their X-ray identification. Oxford Univ Press: 1980; Vol. 5.

55. Jordan, J. W., Organophilic Bentonites. I. Swelling in Organic Liquids. J. Phys. Colloid Chem. 1949, 53 (2), 294-306.

56. Lagaly, G.; Dékany, I., Adsorption on hydrophobized surfaces: Clusters and selforganization. Adv. Colloid Interface Sci. 2005, 114-115, 189-204. 
57. Hedley, C. B.; Yuan, G.; Theng, B. K. G., Thermal analysis of montmorillonites modified with quaternary phosphonium and ammonium surfactants. Appl. Clay Sci. 2007, 35 (34), 180-188.

58. Bershtein, V. A.; Egorova, L. M.; Yakushev, P. N.; Pissis, P.; Sysel, P.; Brozova, L., Molecular dynamics in nanostructured polyimide-silica hybrid materials and their thermal stability. J. Polym. Sci., Part B: Polym. Phys. 2002, 40 (10), 1056-1069.

59. Logakis, E.; Pandis, C.; Peoglos, V.; Pissis, P.; Stergiou, C.; Pionteck, J.; Pötschke, P.; Mičušík, M.; Omastová, M., Structure-property relationships in polyamide 6/multi-walled carbon nanotubes nanocomposites. J. Polym. Sci., Part B: Polym. Phys. 2009, 47 (8), 764-774.

60. Pollatos, E.; Logakis, E.; Chatzigeorgiou, P.; Peoglos, V.; Zuburtikudis, I.; Gjoka, M.; Viras, K.; Pissis, P., Morphological, Thermal, and Electrical Characterization of Syndiotactic Polypropylene/Multiwalled Carbon Nanotube Composites. J. Macromol. Sci., Phys. 2010, 49 (5), 1044-1056.

61. Gómez Tejedor, J. A.; Rodríguez Hernández, J. C.; Gómez Ribelles, J. L.; Monleón Pradas, M., Dynamic Mechanical Relaxation of Poly(2-Hydroxyethyl Acrylate)-silica Nanocomposites Obtained by the Sol-gel Method. J. Macromol. Sci., Phys. 2007, 46 (1), 43-54.

62. Kolodziejski, W.; Klinowski, J., Kinetics of cross-polarization in solid-state NMR: a guide for chemists. Chem. Rev. 2002, 102 (3), 613-628.

63. Azais, T.; Hartmeyer, G.; Quignard, S.; Laurent, G.; Babonneau, F., Solution State NMR Techniques Applied to Solid State Samples: Characterization of Benzoic Acid Confined in MCM-41. J. Phys. Chem. C 2010, 114 (19), 8884-8891. 
64. Azaïs, T.; Tourné-Péteilh, C.; Aussenac, F.; Baccile, N.; Coelho, C.; Devoisselle, J.-M.; Babonneau, F., Solid-State NMR Study of Ibuprofen Confined in MCM-41 Material. Chem. Mater. 2006, 18 (26), 6382-6390.

65. Delle Piane, M.; Corno, M.; Pedone, A.; Dovesi, R.; Ugliengo, P., Large-Scale B3LYP Simulations of Ibuprofen Adsorbed in MCM-41 Mesoporous Silica as Drug Delivery System. J. Phys. Chem. C 2014, 118 (46), 26737-26749.

66. Karol P. Nartowski, D. M., Lucy Hawarden, Juraj Sibik, Dinu Iuga, J. Axel Zeitler, László Fábián and Yaroslav Z. Khimyak, ${ }^{19} \mathrm{~F}$ NMR as a Highly Sensitive Probe Towards Understanding and Direct Monitoring of Confined Crystallisation within Nanoporous Materials. Angewandte Chemie International Edition 2016, DOI: 10.1002/anie.201602936R1.

67. Holmboe, M.; Jonsson, M.; Wold, S., Influence of $\gamma$-radiation on the reactivity of montmorillonite towards $\mathrm{H}_{2} \mathrm{O}_{2}$. Radiat. Phys. Chem. 2012, 81 (2), 190-194.

68. Asano, A.; Shimizu, M.; Kurotsu, T., Effect of Paramagnetic $\mathrm{Fe}^{3+}$ on $T_{1}{ }^{\mathrm{H}}$ in PVA/montmorillonite-clay Nanocomposites. Chem. Lett. 2004, 33 (7), 816-817.

69. VanderHart, D. L.; Asano, A.; Gilman, J. W., Solid-State NMR Investigation of Paramagnetic Nylon-6 Clay Nanocomposites. 1. Crystallinity, Morphology, and the Direct Influence of Fe3+ on Nuclear Spins. Chem. Mater. 2001, 13 (10), 3781-3795.

70. VanderHart, D. L.; Asano, A.; Gilman, J. W., Solid-State NMR Investigation of Paramagnetic Nylon-6 Clay Nanocomposites. 2. Measurement of Clay Dispersion, Crystal Stratification, and Stability of Organic Modifiers. Chem. Mater. 2001, 13 (10), 3796-3809. 
71. Kawakami, K.; Pikal, M. J., Calorimetric investigation of the structural relaxation of amorphous materials: Evaluating validity of the methodologies. J. Pharm. Sci. 2005, 94 (5), 948-965.

72. Roudaut, G.; Simatos, D.; Champion, D.; Contreras-Lopez, E.; Le Meste, M., Molecular mobility around the glass transition temperature: a mini review. Innov. Food Sci. Emerg. Technol. 2004, 5 (2), 127-134.

73. Zoppi, R. A.; Gonçalves, M. C., Hybrids of cellulose acetate and sol-gel silica: Morphology, thermomechanical properties, water permeability, and biodegradation evaluation. $J$. Appl. Polym. Sci. 2002, 84 (12), 2196-2205.

74. Meeus, J.; Scurr, D. J.; Amssoms, K.; Davies, M. C.; Roberts, C. J.; Van den Mooter, G., Surface Characteristics of Spray-Dried Microspheres Consisting of PLGA and PVP: Relating the Influence of Heat and Humidity to the Thermal Characteristics of These Polymers. Mol. Pharm. 2013, 10 (8), 3213-3224.

75. Forrest, J. A.; Mattsson, J., Reductions of the glass transition temperature in thin polymer films: Probing the length scale of cooperative dynamics. Phys. Rev. E 2000, 61 (1), R53-R56.

76. Kang, S.; Hong, S. I.; Choe, C. R.; Park, M.; Rim, S.; Kim, J., Preparation and characterization of epoxy composites filled with functionalized nanosilica particles obtained via sol-gel process. Polymer 2001, 42 (3), 879-887. 
77. Wang, Y.-h.; Wang, W.-h.; Zhang, Z.; Xu, L.; Li, P., Study of the glass transition temperature and the mechanical properties of PET/modified silica nanocomposite by molecular dynamics simulation. Eur. Polym. J. 2016, 75, 36-45.

78. Ellison, C. J.; Torkelson, J. M., The distribution of glass-transition temperatures in nanoscopically confined glass formers. Nat. Mater. 2003, 2 (10), 695-700. 


\section{FIGURES}

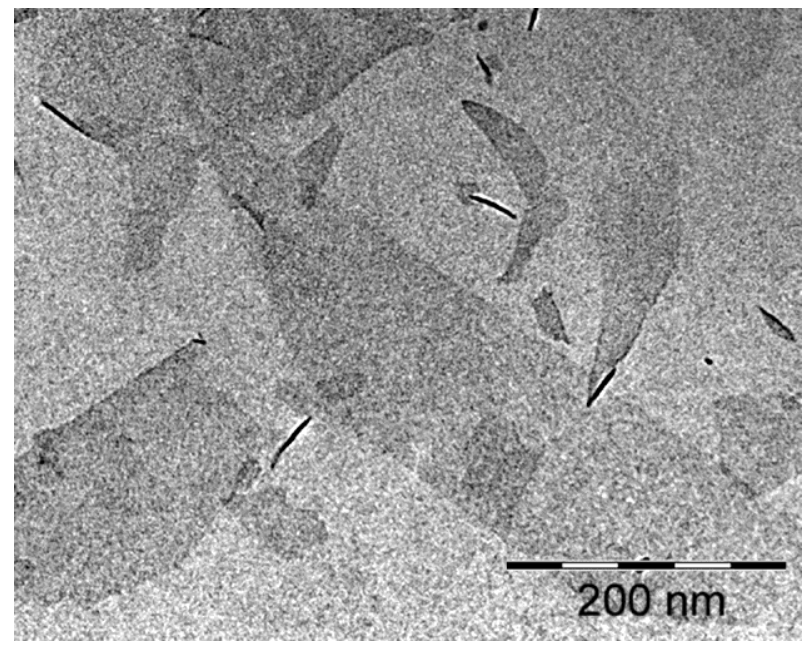

Figure 1. Cryo-TEM image $(100 \mathrm{kX})$ of neat sodium montmorillonite (Na-MMT) in water dispersion. The MMT platelets are seen as dark grey areas, that is, face-on view, or black lines, that is, edge-on view, in the image. 


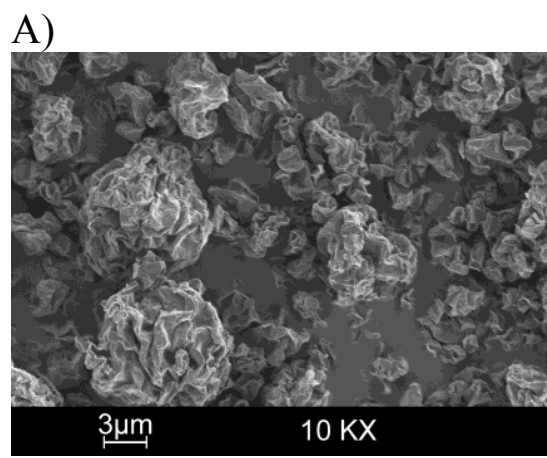

B)

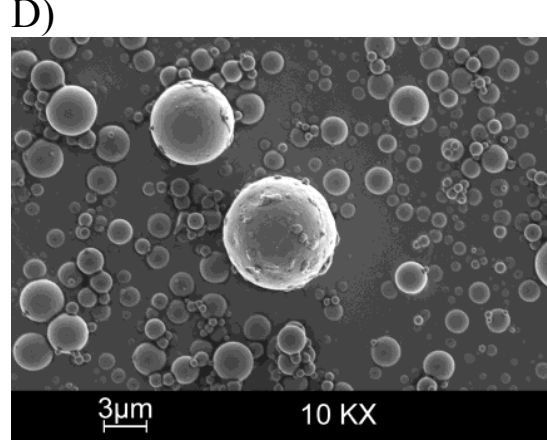

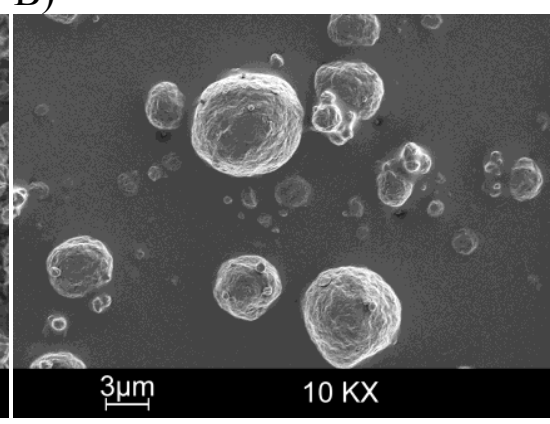

E)

C)

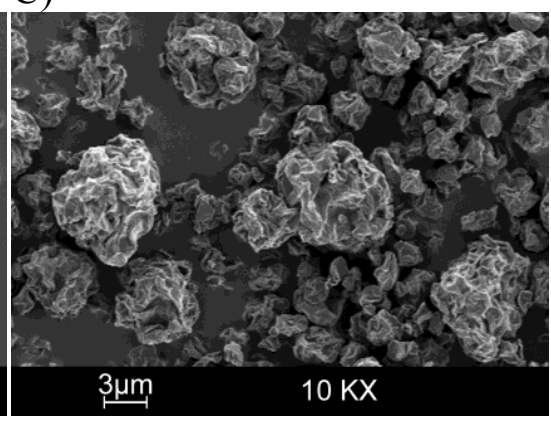

F)

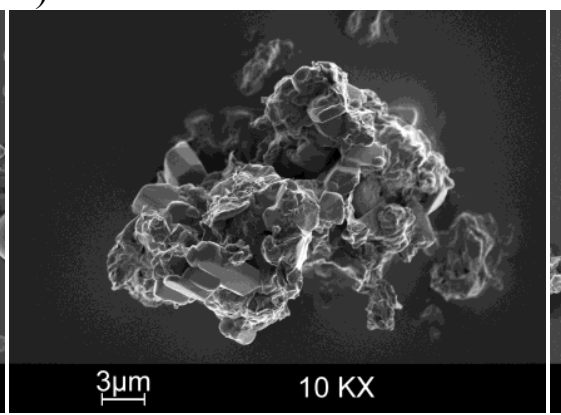

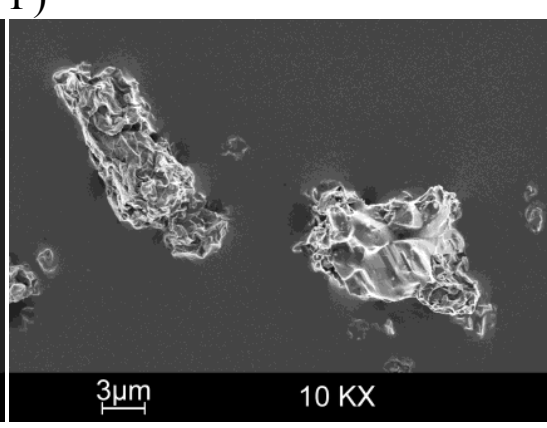

Figure 2. Scanning electron microscopy images of co-spray-dried lactose/sodium montmorillonite (Na-MMT) nanocomposites. A) Neat Na-MMT B) 20\% Na-MMT, C) 80\% NaMMT, and D) neat spray-dried lactose stored over silica gel. E) Humidity stressed 20\% NaMMT, and F) humidity stressed 80\% Na-MMT nanocomposite. 


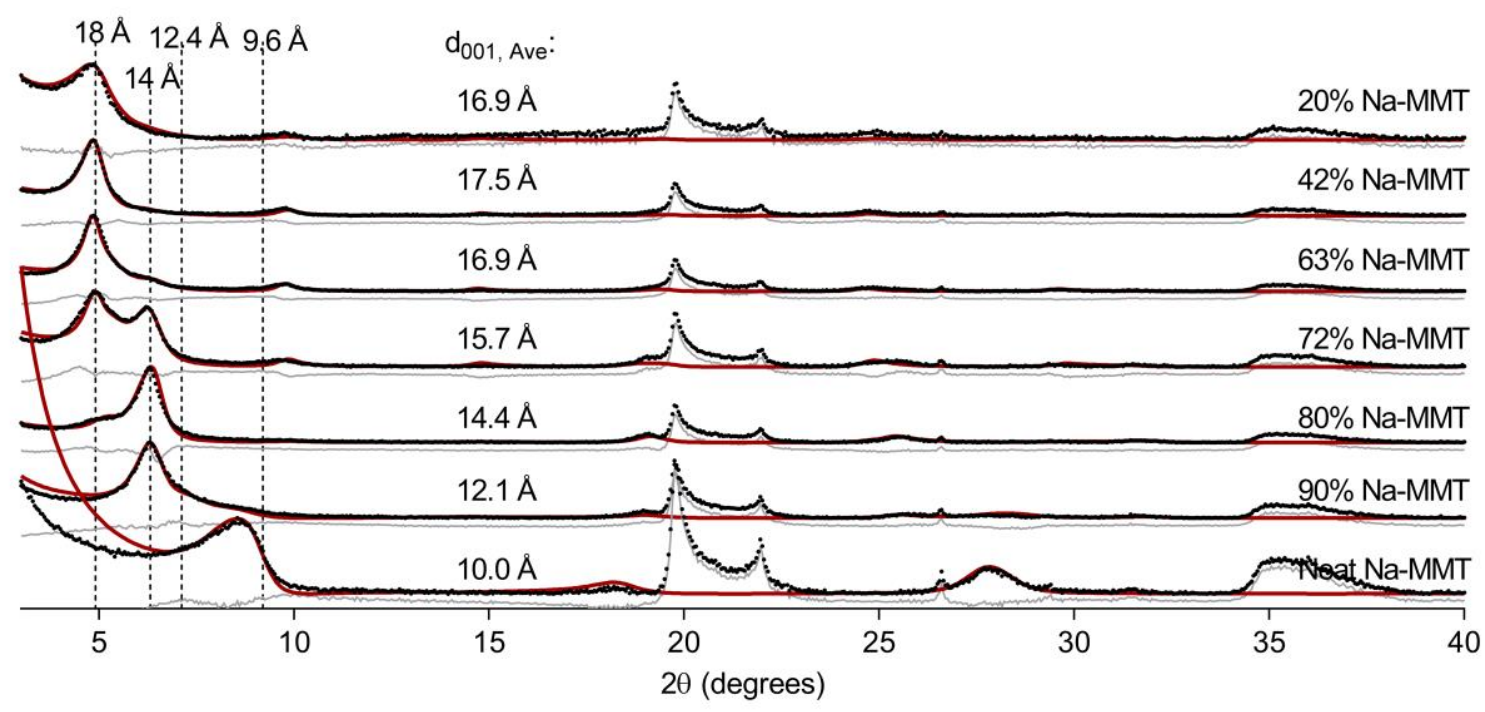

Figure 3. Normalized experimental XRD profiles of for co-spray-dried lactose/sodium montmorillonite (Na-MMT) nanocomposites that have been subtracted from background (black dots), modelled (red curves) XRD profiles, and the deviation (gray curves). 


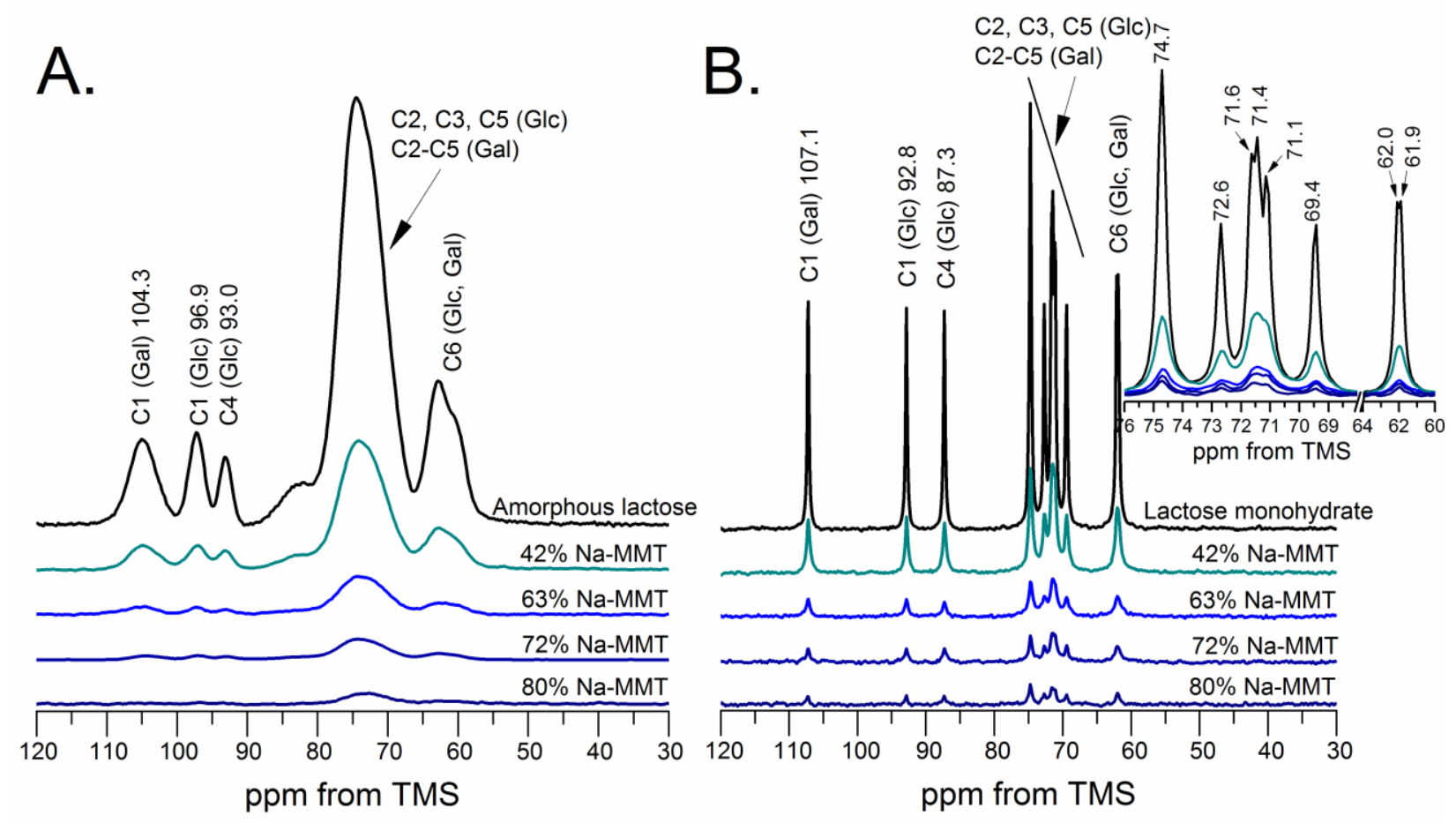

Figure 4. ${ }^{1} \mathrm{H}-{ }^{13} \mathrm{C} \mathrm{CP} / \mathrm{MAS}$ NMR spectra of A) co-spray-dried lactose/sodium montmorillonite (Na-MMT) nanocomposites and B) humidity stressed nanocomposites. The inset demonstrates an enlarged part of Figure 4) from 60 to $76 \mathrm{ppm}$. 

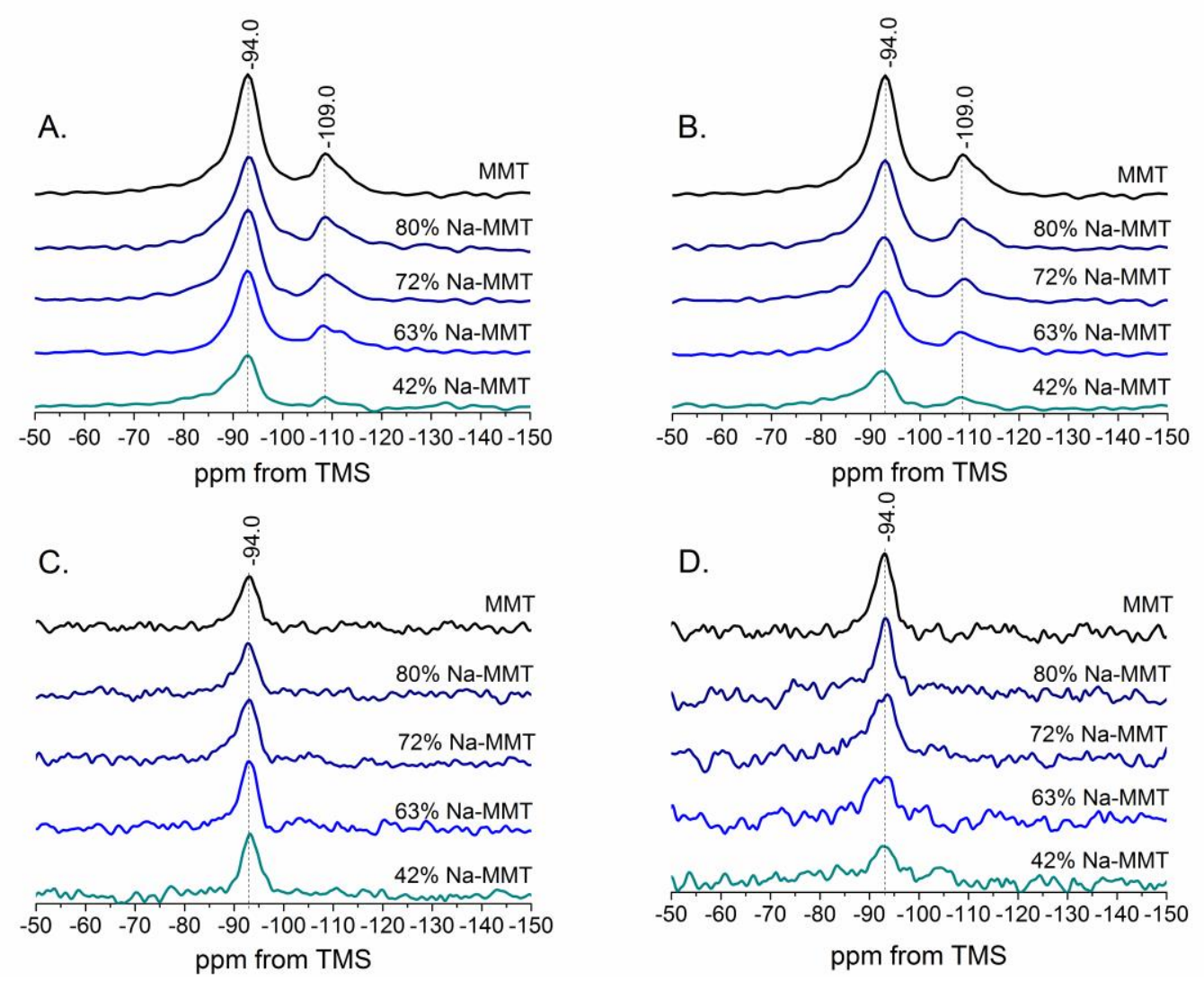

Figure 5. ${ }^{29} \mathrm{Si}$ MAS NMR spectra of A) co-spray-dried lactose/sodium montmorillonite (NaMMT) nanocomposites, and B) humidity stressed nanocomposites. ${ }^{1} \mathrm{H}-{ }^{29} \mathrm{Si} \mathrm{CP} / \mathrm{MAS}$ spectra of C) co-spray-dried lactose/Na-MMT nanocomposites, and D) humidity stressed nanocomposites. 

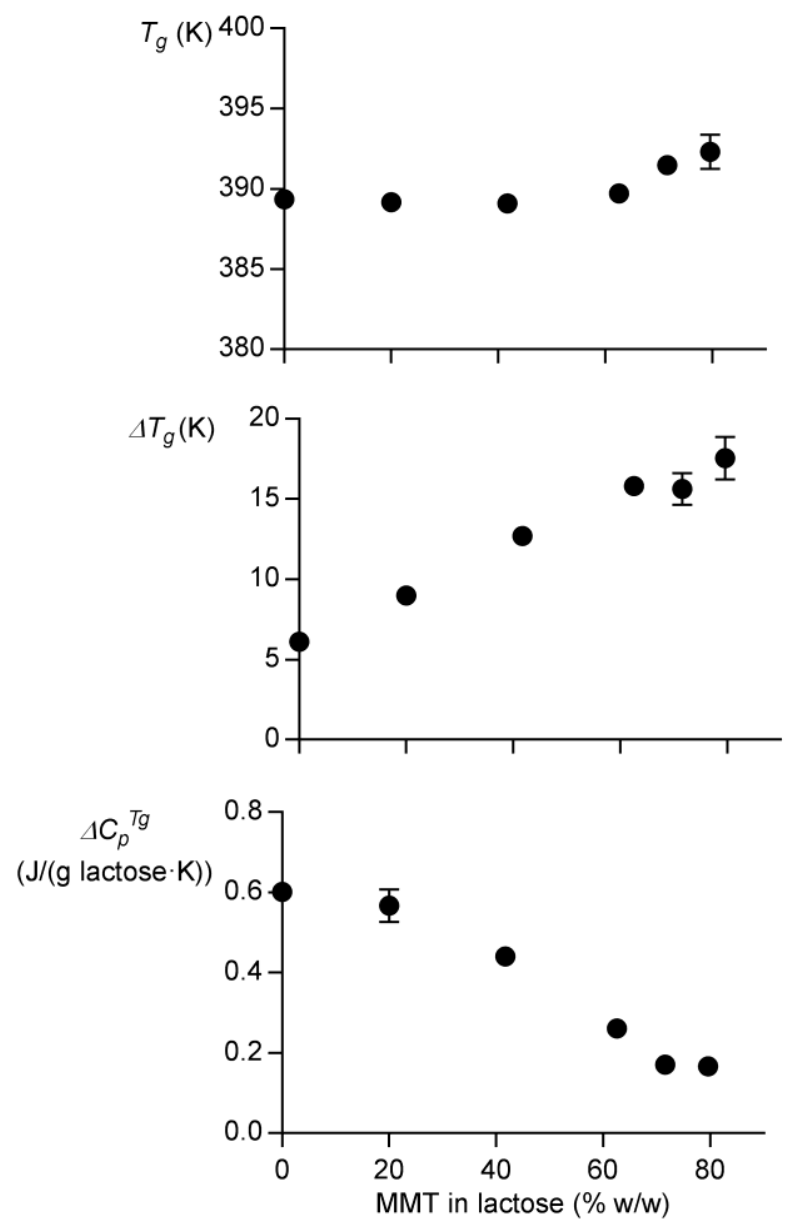

Figure 6. Glass transition temperature $\left(T_{g}\right)$, Glass transition width $\left(\Delta T_{g}\right)$, and the normalized change in heat capacity at $T_{g}\left(\Delta C_{p}^{T g}\right)$ as a function of sodium montmorillonite (Na-MMT) content of co-spray-dried lactose/Na-MMT nanocomposites. Error bars indicate standard error of mean $(\mathrm{SEM})(\mathrm{n}=3)$. 
Nonintercalated lactose

(\% of total lacotse $(w / w)$ )

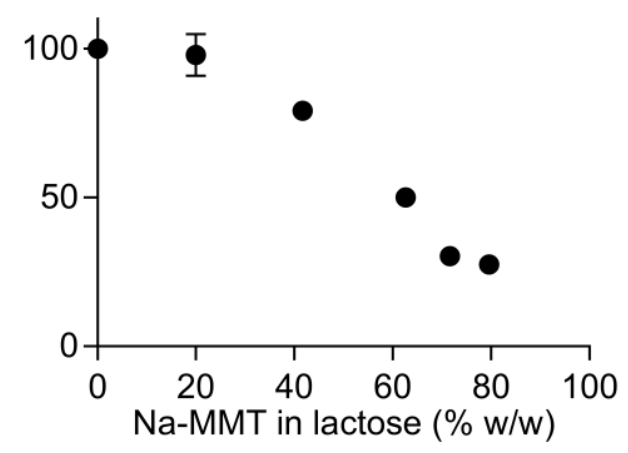

Figure 7. Quantification of non-intercalated lactose on co-spray-dried lactose/sodium montmorillonite (Na-MMT) nanocomposites estimated with mDSC from the normalized change in heat capacity at $T_{g}\left(\Delta C_{p}{ }^{T g}\right)$, assuming that only non-intercalated lactose contribute to the magnitude of $\Delta C_{p}{ }^{T g}$. Error bars indicate standard error of mean (SEM) (n=3). 
TABLE OF CONTENTS (TOC)

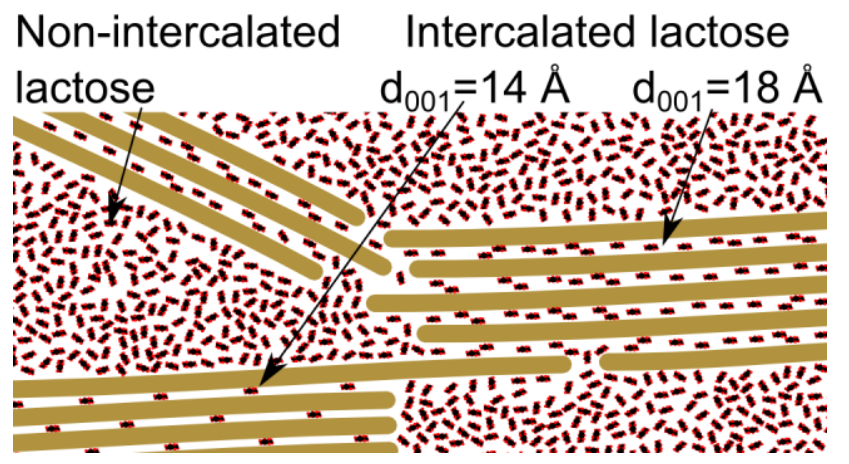

